\title{
Perspective on 25 Years of European Aircraft Noise Reduction Technology Efforts and Shift Towards Global Research Aimed at Quieter Air Transport
}

\author{
Eugene Kors and Dominique Collin
}

\begin{abstract}
This article provides a perspective on 25 years of European aircraft noise reduction technology efforts as well as the gradual shift towards a more global research effort aimed at quieter air transport activity. It covers the following aspects:

1. Introduction - Background and general context of noise from air transport operations

2. European context - ACARE Strategic Research Agendas and establishment of the 2020 and 2050 aviation environmental goals

3. Phased strategy towards 2020 targets and beyond

4. A coordinated European aviation noise research effort

5. Assessment of progress relative to ACARE noise reduction targets

6. Addressing the longer-term objectives - Noise and the ACARE SRIA

7. Community building

8. Lessons learned
\end{abstract}

Keywords ACARE $\cdot$ XNOISE $\cdot \mathrm{ICAO} \cdot \operatorname{Roadmap}$

\section{Introduction-Background and General Context of Noise from Air Transport Operations}

The White Paper, "European Transport Policy for 2010: time to decide", has highlighted the noise issues associated with aviation. "Air transport is having growing problems gaining acceptance, particularly from local residents who suffer from the

Browsing the panorama of noise sources and technologies employed to reduce these noises as well as the trend for future progress. Introducing in this regard the ACARE Agenda and the X-Noise network.

E. Kors $(\varangle)$

Safran Aircraft Engines, Paris, France

e-mail: eugene.kors@safrangroup.com

D. Collin

Retired, Paris, France 
noise generated by airports. Introduction of measures to reduce noise caused by air traffic is a sine qua non if the industry is to continue to grow...."

Despite very significant technology improvements over the past twenty years, and, despite the attention being paid to other environmental impacts, aviation noise remains a major problem in Europe, which has to be solved by the air transport industry as a whole, to deal with the expected growth. Stakeholders and policymakers are faced with the particular challenge that, while noise reduction at source has generally been progressing by leaps, in particular by the evolution of engine concepts, there is a need for an economically viable, but continuously quieter airline fleet to accommodate the expected traffic growth without adverse environmental impact.

In practice, this calls for new, more encompassing systemic approaches, implying that, associated with the successful development of novel technology by manufacturers, additional elements have to be taken into consideration for noise source reduction to meet its goals and play its full role in the face of further air transport development.

International standards governing the noise of newly manufactured aircraft are developed by the International Civil Aviation Organisation (ICAO). In view of the long cycles (research, design, development, production, operation, evolution of infrastructures) involved in the air transport business, its purpose is to provide the needed stability, supporting a global long term view for the manufacturers to anticipate future needs through development of affordable technologies. Within ICAO, standards are being developed by the Committee for Aviation Environmental Protection (CAEP). In 2001 CAEP approved the definition of more stringent noise limits (Chap. 4) effective as of 2006. In the process, to contain any increase in noise exposure beyond the benefits provided by Chap. 2 aircraft phase out (2002), recommendations were made in favour of a Balanced Approach, challenging the ICAO member states to "study and prioritize research and development of economically justifiable technology", besides complementary actions on airport land-use planning and noise abatement operational procedures. A comprehensive Balanced Approach guidance document was completed by ICAO, describing the various steps and instruments, including in last resort such as operational restrictions that could be used to cope with specific airport situations.

The task of monitoring noise technology research programmes has been a particular focus of the International Civil Aviation Organisation (ICAO) since the 6th meeting of its Committee on Aviation Environmental Protection (CAEP/6) in 2004. Over the last ten years, it has been working to develop a broader view of worldwide research activity and place the ambitious goals established for the wider initiatives in perspective.

The first dedicated CAEP Noise Technology Workshop was held in Sao Paulo in December 2001 and information on worldwide noise research efforts has been regularly updated since then. This has included contributions to the Noise Technology Independent Expert Reviews held in 2008 and 2011, as well as the status reports provided to CAEP meetings every 3 years. 
International Noise Technology Research Programmes(2018)



Fig. 1 International Noise Technology Research Programmes as of end of 2018

The latest report presents an overview of noise research efforts up until the end of 2018, covering known national and regional research initiatives and providing an up-to date view of on-going and planned efforts with respect to their technical scope as well as their set objectives (see Fig. 1).

It should be noted that the major initiatives reviewed in 2001 (in the US, EU, and Japan) at the time of the first workshop have been either maintained or expanded, while new significant efforts have been initiated over the years in Canada, the Russian Federation and Brazil, giving us a picture of a truly worldwide effort.

This overview of the research situation demonstrates a significant commitment of all research stakeholders (manufacturers, research establishments, and funding agencies) to investigate and develop novel technology solutions aimed at reducing noise at source. However, it should be noted that beyond the stated research goals, anticipated progress trends will remain conditioned by several factors such as the capability to ensure viable industrial application for promising technology breakthroughs as well as the commitment to maintaining steady funding over a significant period of time.

As part of its global forecasting effort, developing a forward view on technological developments was deemed essential for CAEP and in 2007 a process was initiated to develop mid and long term ICAO Noise Technology Goals by means of an Independent Experts panel reviewing potential achievements from research programmes worldwide. Dedicated Noise Technology Reviews were organised in 2008 and 2011 
for the Experts Panel to establish a full set of CAEP Noise Technology goals (reported at the CAEP/9 plenary meeting of February 2013).

Originally related to the modeling and forecasting effort, CAEP also got focused on the issue of Impacts, inviting in 2007 worldwide experts to a dedicated workshop. Within this context, the evaluation and measure of Annoyance in particular attracted attention, the registered situation at main airports leading to question the precedence of aircraft noise levels over the frequency of operations as the critical factor. A second workshop was organised in 2015, paving the way for a white paper in noise effects produced at the occasion of the CAEP/10 meeting (February 2016).

Focusing now on the European regulatory context, the European Commission issued in 2002 a directive (DG TREN 2002/30/EC «Noise Related Operating Restrictions at Community Airports» aimed at implementing the Balanced Approach at EU level and harmonising strategies for establishing local airport operational restrictions. The same year, another directive (DG ENV 2002/49/EC « Assessment and Management of Environmental Noise», referred to below as END) was issued within the framework of an overall EU Noise Policy to achieve an evaluation of the baseline situation across the transport modes and subsequently define local action plans based on the resulting noise maps. Directive 2002/30/EC was recently updated as European Regulation 2014/598/EU, extending the scope of aircraft that could be submitted to local operational restrictions.

\section{European Context-ACARE Strategic Research Agendas and Establishment of the 2020 and 2050 Aviation Environmental Goals}

Since 1995, through the early work of the Aeronautics Task Force on "The Environmentally Friendly Aircraft" and subsequent work by the Advisory Council for Aeronautics Research in Europe (ACARE), there has been a definite will to develop a consistent research strategy aimed at addressing Aviation Environmental issues on a problem-solving basis.

This priority was reflected in the 2001 report of the Group of Personalities "European Aeronautics - a Vision for 2020+" on meeting society's needs and winning global leadership. In particular it addressed the goals of reducing perceived noise to one half of current average levels eliminating noise nuisance outside the airport boundary by day and night through quieter aircraft, better land-use planning around airports and systematic use of noise reduction procedures. 
Taking up on these goals, the first edition (2002) of the Strategic Research Agenda (SRA) issued by the Advisory Council for Aeronautics Research in Europe (ACARE) promoted the development of an appropriate strategy encompassing:

- The elaboration of technology development strategies aimed at a new generation of noise reduction means for both fixed wing aircraft and rotorcraft, including the associated adaptation of research infrastructures, in particular tests and computing facilities, and covering potential synergies with national efforts.

- The elaboration of an action plan aimed at taking advantage of technology advances in aircraft and air traffic systems to favour implementation of environmentally friendly operational practices such as noise abatement procedures (NAPs).

- The elaboration of a development plan for impact assessment tools and instruments aimed at improved airport noise planning and environmental management practices.

The proposed approach clearly mirrored the Balanced Approach concept and aimed at setting the conditions for a successful implementation of ICAO's recommendation from the early steps of research. This was further substantiated by way of a quantified target addressing the first noise objective of Vision 2020, translated in quantitative terms as an average reduction of 10 decibels per aircraft operation (departure or landing), taking into account technology benefits (Source noise Reduction) as well as operational improvements (Noise Abatement Procedures).

Moving further along these lines, in 2011, the report "Flightpath 2050_Europe's Vision for Aviation" issued by the High Level Group on Aviation Research did set a new target for 2050, stating that by then "the perceived noise emission of flying aircraft is reduced by $65 \%$ relative to the capabilities of typical new aircraft in 2000 ".

To address the targets set by Flightpath 2050, the 2012 ACARE Strategic Research and Innovation Agenda (SRIA) aimed at the 2035/2050 timeframes confirmed the importance of addressing the impacts aspects as part of a coordinated research strategy, stating that the targeted $65 \%$ noise reduction relative to the 2000 situation "should be achieved through a significant and balanced research programme aimed at developing novel technologies and enhanced low noise operational procedures, complemented by a coordinated effort providing industry, airports and authorities with better knowledge and impact assessment tools to ensure that the benefits are effectively perceived by the communities exposed to noise from air transport activities".

The general approach to ACARE 2020 and 2050 environmental objectives is summarised in Fig. 2. 


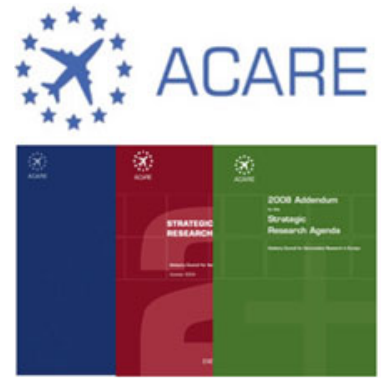

SRA - 2002, 2004 \& 2008

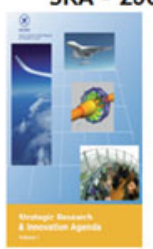

SRIA - $2012 \& 2017$


2050 relative to 2000

Fig. 2 ACARE environmental objectives

Further on, the 2017 update version of the SRIA maintained these noise reduction goals while stating the ever stronger focus on emissions reduction. This emphasized the need to look after and understand the issue of environmental interdependencies whether on technology, operational measures and overall impacts.

Finally, in its 2021 document "Time for change-the need to rethink Europe's FlightPath 2050", ACARE is re-affirming its environmental commitment stating that "societal expectations on $\mathrm{CO}_{2}$ mitigation have strongly increased, especially in the field of aviation. Aviation has been pinpointed as a potential major contributor to $\mathrm{CO}_{2}$ emissions and global warming, although it is currently estimated that the aviation industry represents only approximately $2 \%$ of global human-induced $\mathrm{CO}_{2}$ emissions. The ratified Green Deal objectives demand that the European aviation sector achieves drastically reduced emissions by 2030 and climate neutral aviation by 2050 . These targets include emissions, air quality and noise around airports, and ECO-design and end-of-life recycling. This societal change demands disruptive technological solutions; conventional technologies are not enough. New energy sources need researching, integrating, and deploying as new generation aircraft types enter airline fleets". 


\section{Phased Strategy Towards 2020 Targets and Beyond}

The first noise 2020 objective defined by the ACARE SRA-1 aimed at reducing noise emission of flying vehicles by half, which can be translated in quantitative terms as an average reduction of 10 decibels per aircraft operation (departure or landing), taking into account technology benefits (Source noise Reduction) as well as operational improvements (Noise Abatement Procedures).

The two contributors identified to achieve the reductions associated with the $-10 \mathrm{~dB}$ were further described in terms of associated technical and operational solutions as shown below:

- Source Noise Reduction associated solutions: Noise Reduction Technologies (NRT generation 1 and 2), Novel aircraft and engine/powerplant architectures

- Noise Abatement Procedures associated solutions: Improved Operating Practices with Current Concepts/Optimised Operations with New Technology/ATM-ATC Integration

The second noise objective defined by the SRA-1 aimed at ensuring that the $10 \mathrm{~dB}$ benefit in noise emission anticipated for fixed-wing aircraft effectively led to there being no impacted people outside airport boundaries, provided the appropriate management practices are in place.

As shown in Fig. 3, to address the $-10 \mathrm{~dB}$ noise target, a phased approach was developed aimed at meeting an interim 2010 target of $5 \mathrm{~dB}$ with the help of

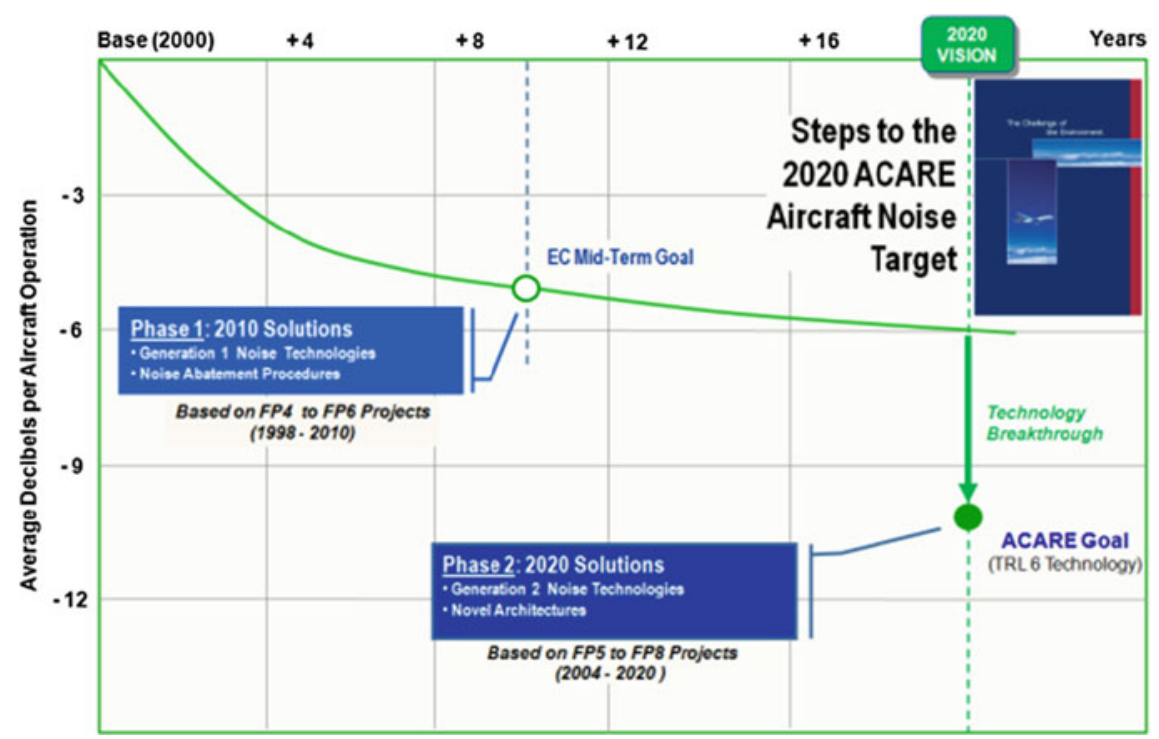

Fig. 3 Steps to ACARE 2020 noise target 
more readily (higher TRL) available solutions, paving the way for the technology breakthroughs needed to achieve the full target in 2020 .

To lay out the foundations of the following phase, namely addressing the $65 \%$ noise reduction target set by Flightpath 2050 and the 2012 ACARE Strategic Research and Innovation Agenda (SRIA), a complete set of recommendations were expressed aiming at the 2035/2050 timeframes, identifying solutions capable by 2050 of reducing noise at departure and arrival by $15 \mathrm{~dB}$ per operation relative to Year 2000 .

On top of expected 2020 achievements, anticipated solutions would involve the development of a 3rd Generation of Noise Reduction Technologies (NRT), relying in particular on active and/or adaptive techniques to reduce the noise of engines, landing gears and high-lift devices. The emergence of novel aircraft configurations was also considered an essential factor in ultimately delivering the needed source noise reduction. In the shorter term, advanced tube and wing concepts associated with ultra-high by-pass ratio propulsion concepts should provide through masking effects an anticipated $2 \mathrm{~dB}$ contribution to the ACARE target. In the longer term, wider options associated blended-wing body concepts such as embedded nacelles or distributed propulsion systems should also significantly contribute to further noise reduction. A broad view of the anticipated solutions is presented in Fig. 4.

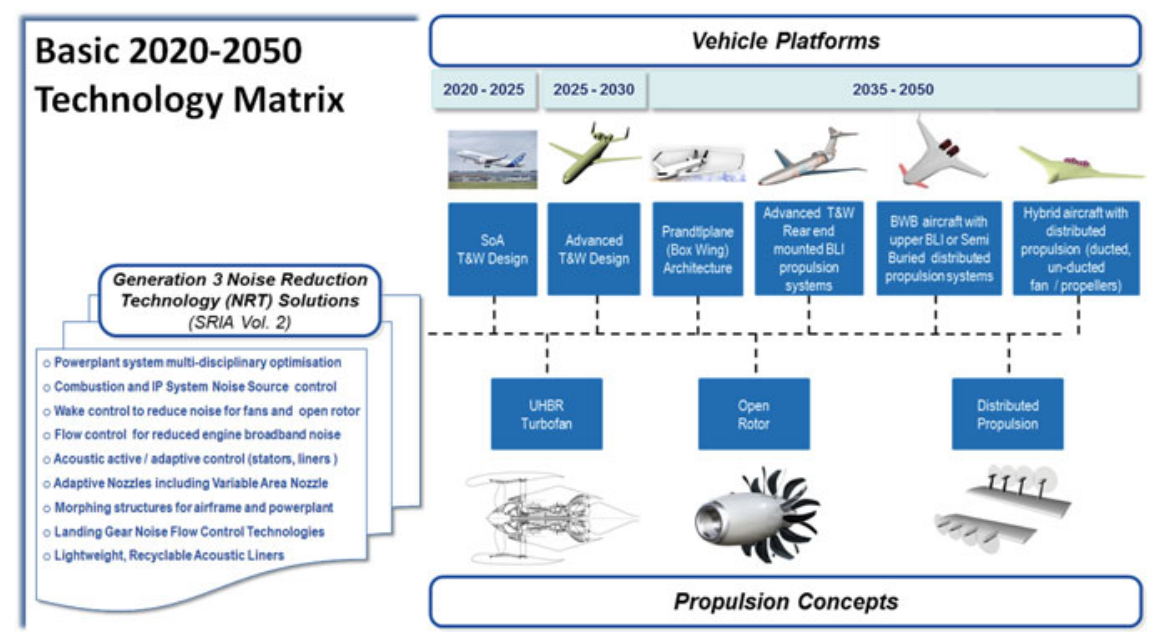

Fig. 4 Basic 2020-2050 Technology Matrix 
Moreover, in order to exploit new technology and low noise operations developments and to enable integrated impact mitigation solutions, it was considered of utmost importance to:

- improve and continuously update the understanding of how noise from air transport operations implemented through new Air Traffic Management solutions affects people

- provide the technical support to successful implementation of planning policies compatible with traffic growth for the long term benefit of the communities.

In line with this comprehensive strategy, a number of "Enabling Factors" foreseen as key contributors to the 2050 noise goal achievement were pointed out, namely:

- improved numerical simulation capabilities, together with test facilities incorporating advanced measurement techniques, in order to support further noise reduction at source level as well as the implementation of multi-disciplinary optimisation techniques and aircraft/engine integrated design practices contributing to lower noise through efficient integration of noise reduction solutions, reduced weight, decreased drag, improved powerplant efficiency and flight path design,

- stimulated advances in related technology areas, such as materials and electronics, to allow the introduction of novel low noise technologies, including active/adaptive techniques,

- updated, internationally recognised, Annoyance and Sleep Disturbance models, taking into account the evolution of aircraft noise signatures and traffic conditions (multiple events), also considering airport specificities,

- tools supporting transparent communication policies covering relevant indices, flight path / operations on-line forecast and tracking as well as comprehensive assessment of environmental interdependencies and monetisation of impacts.

Detailed recommendations were provided along these lines by the noise research community to ACARE and included in the Volume 2 of the SRIA which included the foreseen solutions for all areas. These are summarised in Fig. 5.

In fact, the ACARE SRIA confirmed the importance of addressing the impacts aspects as part of a coordinated research strategy, stating that the targeted $65 \%$ noise reduction relative to the 2000 situation "should be achieved through a significant and balanced research programme aimed at developing novel technologies and enhanced low noise operational procedures, complemented by a coordinated effort providing industry, airports and authorities with better knowledge and impact assessment tools to ensure that the benefits are effectively perceived by the communities exposed to noise from air transport activities".

This successive set of strategic recommendations shaped the overall noise research effort implemented to this day. In face of the diversity of anticipated solutions, it also called for efficient coordination from the early stage such an effort to ensure achievement of the noise targets. 


\section{SRIA Volume 2: 2035 / 2050 Solutions}

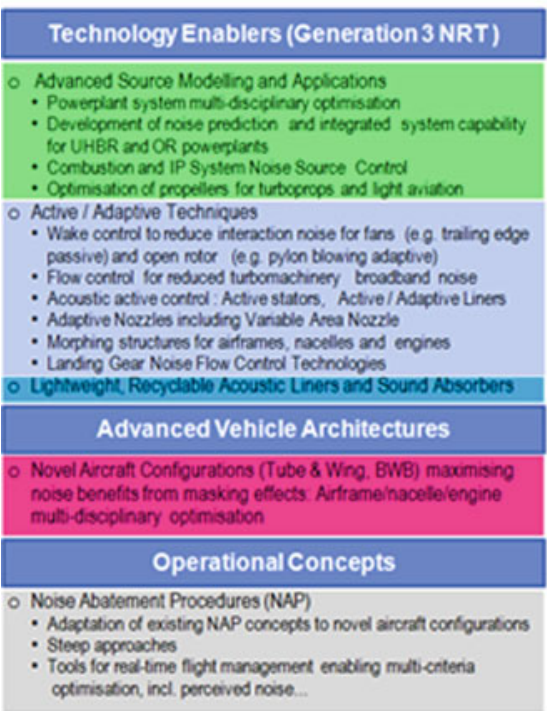



Management of Noise Impact Enablers

\begin{tabular}{|c|}
\hline 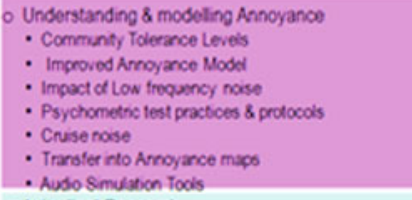 \\
\hline 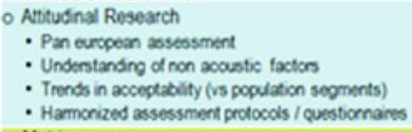 \\
\hline $\begin{array}{l}\text { - Metrics } \\
\text { - Number of Everts Above a limt vs LDEN } \\
\text { - Annoyance per flight (exposure x pogulation) } \\
\text { - Index for nose shanno }\end{array}$ \\
\hline $\begin{array}{l}\text { - Communication } \\
\text { - Methe understood by the putic } \\
\text { - Indvidual benofits for communty members } \\
\text { - Flyover sound simulation with auralzation } \\
\text { - } 30 \text { filght tracks maps }\end{array}$ \\
\hline $\begin{array}{l}\text { - Health ind des } \\
\text { - Epidemiological studes } \\
\text { - Sloep nosearch } \\
\text { - Other heath oulcomes (eg, blood prossure) }\end{array}$ \\
\hline
\end{tabular}

Vol2 avalable at http:ilwww acare4europe.org/acare-db

Fig. 5 ACARE SRIA Vol. 2035-2050 solutions from air transport noise mitigation

\section{A Coordinated European Aviation Noise Research Effort}

\section{Overall Approach to Coordination}

To implement the phased strategy described in the previous section, a coordinated approach was established. The basic concept of the European Aviation Noise Research Network (X-NOISE) emerged in a similar timeframe as the ACARE SRA.

From 1998 to 2015, based on the 3-Pllar approach described in Fig. 6, the network concept demonstrated its ability to accommodate the evolution of the broader context and provide key support in the definition and implementation of a research strategy aimed at reducing the impact of noise from air transport. It established well recognized dissemination and communication features and developed an active research community covering a vast majority of EU member states. Working around a common set of priorities and objectives, it also favored a better exploitation of innovative upstream research developed at national level into larger European projects aimed at downstream research. 


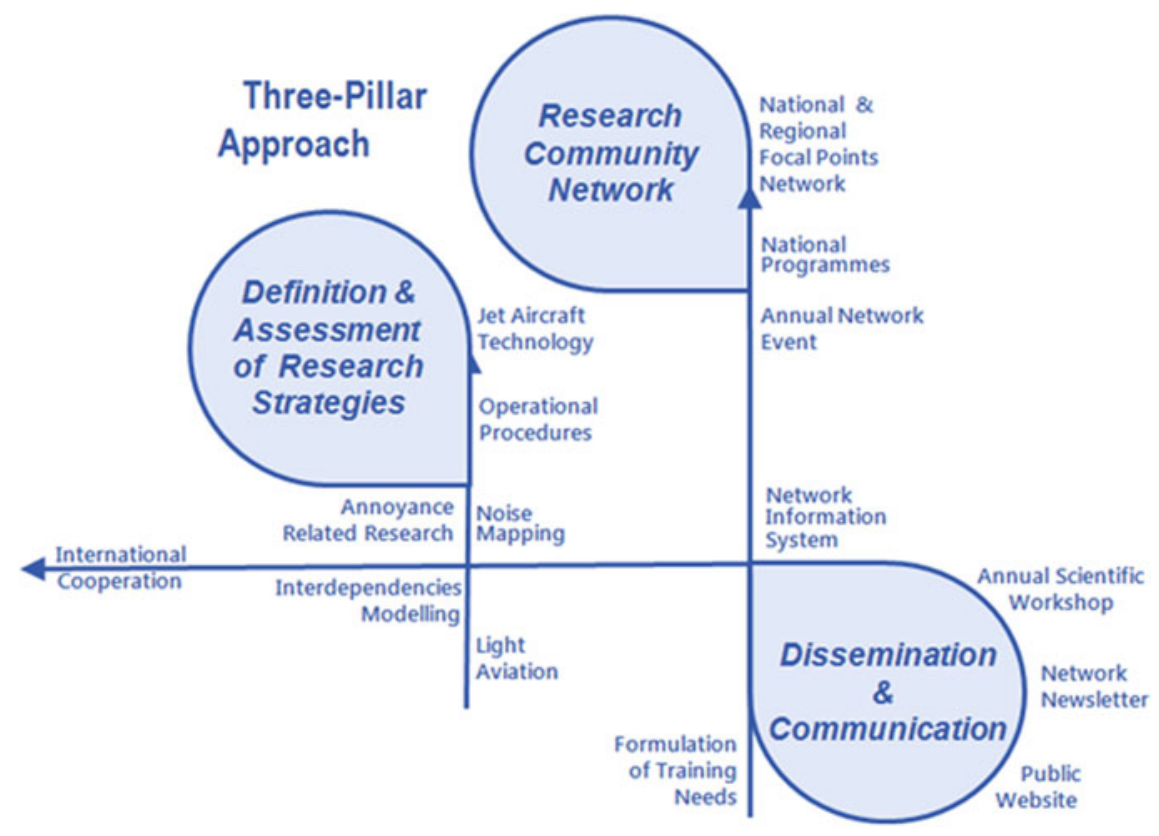

Fig. 6 Three-Pillar approach to networking and coordination activities

Within the specificity of the European general framework supporting collaborative research, the effective implementation of the phased strategy is best represented by the roadmap of European research projects directly contributing to the 2020 noise target achievement and supporting the early steps towards the 2050 target (Fig. 7).

As can be seen, over 25 years, more than 35 noise dedicated projects aimed at implementing the ACARE agendas were launched and complementary efforts on operational procedures and noise impacts initiated. Noise reduction was also supported through significant participation in large architecture-oriented multidisciplinary projects such as VITAL, DREAM, ENOVAL and CLEAN SKY.

This resulted from a significant mobilisation of research actors, achieving a well balanced participation between Industry and Research Organisations from a large majority of EU and Associated States. Definite steps was also taken towards wider international cooperation, in particular with countries actively involved in discussing international aviation noise standards within ICAO/CAEP such United States, Canada, Russia, Japan and Brazil.

Following the last X-NOISE project completed in 2015, a new phase in research coordination was then implemented in 2017 building on the X-NOISE legacy, supported by the ANIMA project with the following objectives:

- Establish and update through a scenario-based approach a common strategic research roadmap for aviation noise reduction, addressing the development of new technologies and methodologies. 


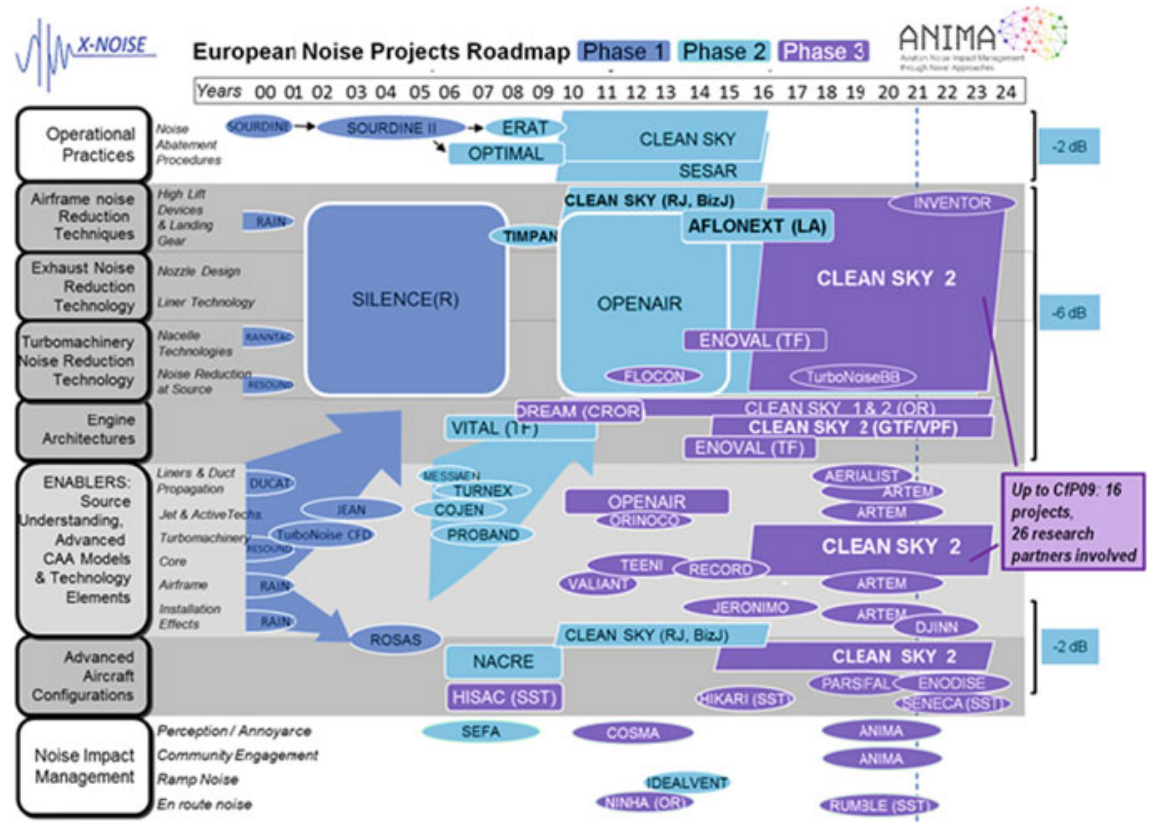

Fig. 7 Roadmap of European Union funded projects relating to aircraft noise

- Coordinate a European wide network of experts and research actors in support of the roadmap process, stimulating the emergence of novel approaches to overcome gaps, ensuring minimal duplication and fragmentation in the course of future research efforts.

- Explore possibilities, facilitate and establish practical conditions for targeted international collaboration in line with the strategy for EU international cooperation in research and innovation as well as the needs put forward by the strategic roadmap for aviation noise, including aspects related to international regulatory discussions.

Aspects pertaining to the common strategic research roadmap are further developed in Section "Establishing the Common Strategic Research Roadmap for Aviation Noise Reduction"

The networking aspects, lessons learned and possible ways forward will be further developed under Section "Community Building" and "Lessons Learned" 


\section{Noise Reduction at Source-Technological Achievements and Perspectives}

A key contributor in impulsing the whole research effort was the SILENCE(R) project, funded under the 5th Framework 'Growth' programme. SILENCE(R) remains to this day the largest project devoted to aircraft noise ever supported by the European Commission for a total budget of 111 Million Euros. Completed in 2007, the 6-year project involved a consortium of 51 partners and focused on the development of aircraft noise reduction technologies (NRT) Generation 1. Research activities were being carried out in various fields, such as Engine Source Noise, Nacelle Technologies, and Airframe Source Noise and Active Control Applications. More than 35 prototypes were to be tested during the SILENCE(R) programme.

In a number of ways, Silence(R) established a blueprint for larger EU funded research projects to come through its effective risk management approach and the first implementation of a dedicated Technology Evaluation process, which proved to be both a valuable tool in decision making and a key asset to assess the progress made to this day relative to ACARE 2020 noise target.

As can be seen on Fig. 8, at project end, thanks to two dedicated flight tests on the A320 and the A340 as well as a number of engine full scale tests, ten new

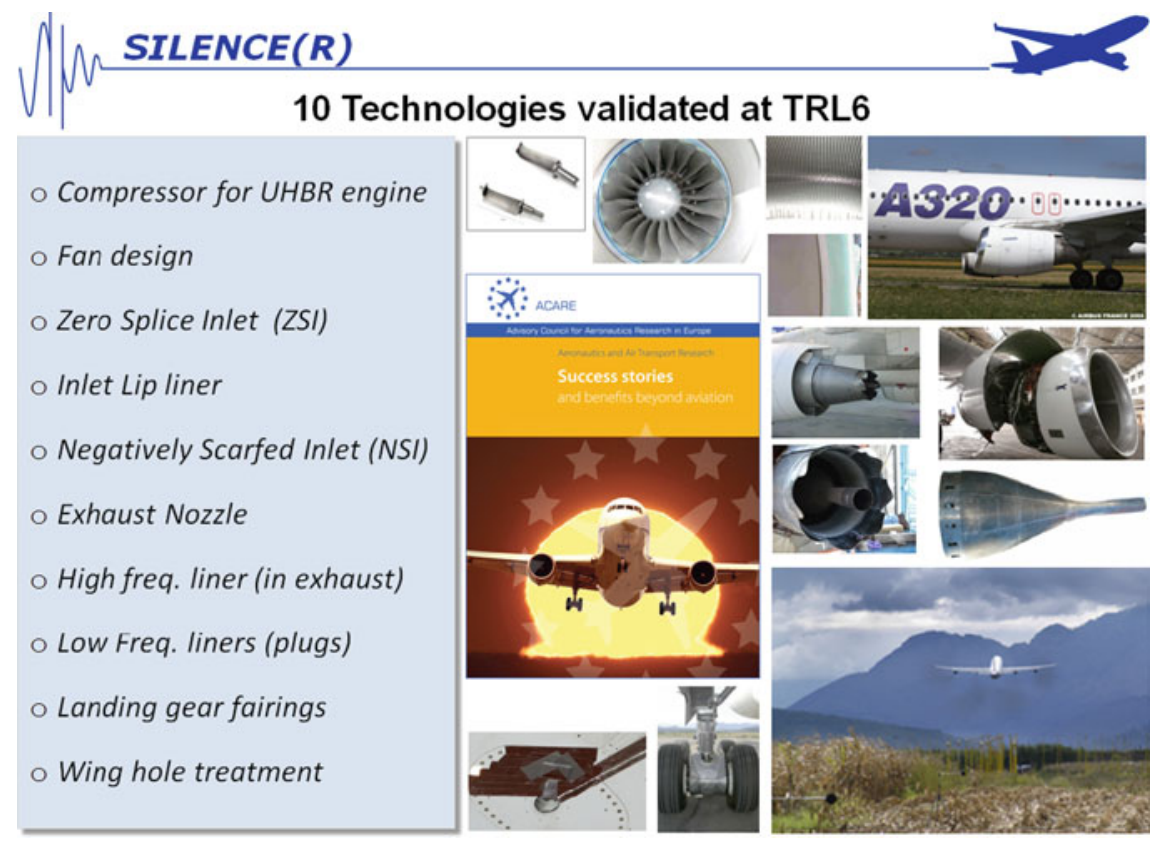

Fig. 8 Overview of SILENCE(R) key technologies 
technologies were validated from the noise reduction standpoint. These technologies were considered mature enough for further work aimed at successfully addressing through industrial development work the design tradeoffs issues pointed out by the technology evaluation process.

A significant effort was subsequently dedicated to technology enablers throughout the 6th Framework programme, focusing on advanced methods for prediction of fan noise, jet noise and nacelle liners efficiency together with low TRL airframe noise reduction concepts. Further maturation of Generation 2 NRT solutions aimed at all significant noise sources was then achieved through the OPENAIR and AFLONEXT projects.

In terms of achievements, the noise reduction at source effort aimed at both 2020 targets and 2035 horizon can be divided into three headlines:

- Maturation and validation of Generation 2 powerplant and airframe noise reduction technologies

- Enabling development of Generation 3 solutions (prediction tools and advanced technology concepts)

- Contribution from novel propulsion concepts and novel aircraft configurations.

\section{Maturation and Validation of Generation 2 Powerplant and Airframe Noise Reduction Technologies}

Maturation of Generation 2 noise reduction technologies dedicated to engine noise reduction was mostly performed in the OPENAIR project including noise suppression techniques to cover the key sources of fan and jet noise. The following technologies were successfully matured to TRL4.

MDO Outlet Guide Vanes (OGVs) and Lined OGVs: Multi-disciplinary Optimised (MDO) OGVs and the Lined OGVs have been designed with a large reduction of the number of vanes $(\sim 10)$ compared to the traditional configuration $(\sim 40)$. This enabled thin blade designs with special shapes and thicker blade designs that permit internal space for acoustic liners. Design objectives balanced aerodynamic performance and acoustic design. Both broadband and tonal noise sources were reduced, whilst leaving the aerodynamic performance unchanged as demonstrated on large scale fan rig.

Intake Technologies: Various new inlet liner concepts, based on recent advancements in Computational Aero Acoustics (CAA) have been developed and tested on a fan rig. The "Folded Cavity Liner" has a geometry that allows low frequencies to be damped through a large space that is folded behind the conventional liner, so that lower nacelle thickness can be used compared to conventional designs. Forward fan noise reductions have been achieved, in addition to a significant reduction of the buzzsaw noise, which is an annoying noise source also audible in the cabin.

Highly Curved Bypass duct: The highly curved bypass duct seeks to open out the duct earlier to a higher radius. This results in a reduced height duct with a greater liner area per unit length. These attributes allow a shorter nacelle to be used giving significant reductions in weight and drag. 
Acoustically lined splitters and fins: Configurations of supplementary liner area in the bypass duct were designed and tested on a large scale fan rig. Both "splitters", which fully cover the height between the inner and the outer wall, as well as socalled "fins", which protrude from the outer wall up to about halfway of the duct height were investigated. These may provide a solution to the acoustic area loss when shorter nacelles are desired in the future.

Negatively Scarfed Nozzles: The scarfed shape changes the directivity of the rearward radiated fan noise to higher angles and provides a general reduction in the total engine noise. Scarfed nozzles have been designed for the secondary nozzle of both short and long cowl nacelles and tested in an anechoic wind tunnel.

Active Stator: Research efforts on this active noise control technology have been pursued with improved actuators, sensors and algorithms. Objectives were extended to include also rearward fan noise control, in addition to the already demonstrated forward fan noise control. The new system was validated on a large scale fan rig. Integration aspects were matured in parallel through a full scale composite OGV demonstrator.

Active Nozzle: Various active flow/noise control concepts have been explored before selecting the "Microjet" technology for large scale testing wind tunnel testing. Extensive integration studies have been performed in parallel on the air supply through the nacelle to the primary and secondary nozzles.

Through OPENAIR, CLEAN SKY and AFLONEXT, technologies were developed to reduce the noise of landing gears and high lift devices. While CLEAN SKY focused on solutions aimed at regional aircraft, OPENAIR and AFLONEXT investigated and validated techniques for larger commercial models.

Low Noise Landing Gear: Wind tunnel tests at full and reduced scale have been carried out on both wing-mounted and fuselage-mounted landing gears for large airliners and regional aircraft. Amongst all tested configurations, showed the highest noise reductions:

- For the large aircraft fuselage-mounted gear: Torque link mesh fairing, deceleration plate

- For the large aircraft wing-mounted gear: Low noise dressing routing; Forward location for cardan pin; Torque link mesh fairing; Door aligned with flow; H-shape side-stay with spring and large side-stay mesh fairings.

- For the regional aircraft main and nose landing gears: Low Noise Concepts including landing gear bay acoustic treatments, strut fairings and wheelpack fairings (covers, hubcaps, wind shields).

Adaptive Slats: In the adaptive slat concept, the trailing edge of the slat is a flexible morphing structure that can fully close the gap between the wing and the slat. In normal operation with low angle of attack, the gap is closed and quiet.

Droop Nose: This solution consists in a smart hingeless, gapless, leading edge highlift device, based on a rotational drive concept assisted by SMA actuators. The device extends up $67 \%$ wing span due to structural/system installation constraints. The "skewed" configuration is aimed at avoiding streamwise longitudinal gaps in the retracted position. 
Porous Flap Side Edge (PFSE): Various acoustically porous materials were evaluated for their environmental (certification) requirements before a final selection was manufactured for large scale acoustic testing at the DNW The PFSE proved an effective means of reducing noise without any significant aerodynamic penalty.

Lined Flap: Innovative, acoustically treated, low noise trailing edge flap conceived as a sound-absorption integrated multilayer liner structure with micro-perforation on the external facing sheet.

Morphing Flap: An advanced structure has been conceived to match an aerodynamically optimised "target shape". Morphing performance of two architectures was demonstrated on 2D mechanical prototypes: Smart Actuated Compliant Mechanism (SACM) and Deeply Embedded Smart Actuator (DESA).

Despite being only a third, budget wise, of the Silence(R) project, more than 50 engine and airframe oriented technology developments took place in OPENAIR, all executed around a number of key technologies identified at project start. From this set, the technologies described above achieved TRL4/5 through large scale testing in wind tunnels and/or dedicated engine fan or exhaust rigs.

Part of the 50 technology developments were as risk-reduction, backup or long term solution related to the key technologies. A total of 144 low TRL ideas were collected before project start in an "innovative concepts" database from which the project selected 19 for inclusion in OPENAIR. This approach was perceived as very successful for OPENAIR and other related projects and proposed for best practice in the future.

On the aircraft side, the project AFLONEXT successfully advanced further maturation of airframe noise reduction technologies, flight testing in 2018 a series of flap and main landing gear solutions.

The scope of technology development achieved in OPENAIR, CLEAN SKY and AFLONEXT is represented in Figs. 9, 10 and 11.

\section{Enabling Development of Generation 3 Solutions (Prediction Tools and Advanced Technology Concepts)}

These activities are aimed at supporting advanced noise reduction technologies (Generation 3) for industrial application in the 2030 + timeframe. Recent developments are reported for each of the main areas of research and projects featured in the Fig. 7 roadmap. 

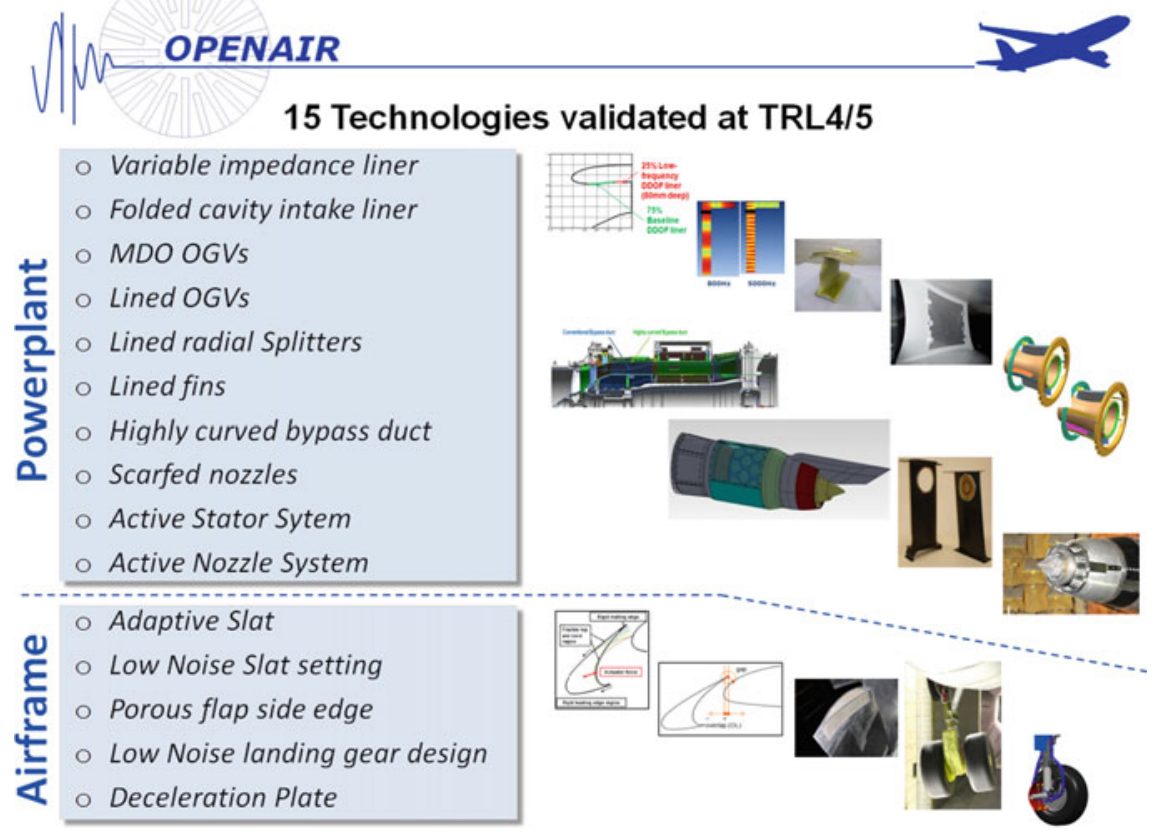

Fig. 9 Overview of OPENAIR Key technologies

\begin{tabular}{|c|c|c|c|c|}
\hline $\begin{array}{l}\text { Gapless Architectures } \\
\text { Morphing Flap, Droop Nose }\end{array}$ & \multicolumn{2}{|c|}{$\begin{array}{l}\text { Active Flow Control } \\
\text { Synthetic Jets }\end{array}$} & $\begin{array}{l}\text { Passive means } \\
\text { Liners, Fences }\end{array}$ & $\begin{array}{l}\text { Low-Noise } \\
\text { High-Lift Devices }\end{array}$ \\
\hline \multicolumn{2}{|c|}{$\begin{array}{l}\text { Aerodynamic Fairings } \\
\text { Strut covers, wheelrim caps }\end{array}$} & \multicolumn{2}{|c|}{$\begin{array}{l}\text { Bay cavity \& Doors treatments } \\
\text { Acoustic Liners }\end{array}$} & $\begin{array}{l}\text { Low-Noise } \\
\text { Landing Gears }\end{array}$ \\
\hline
\end{tabular}

Fig. 10 Scope of investigated airframe noise solutions in CLEAN SKY



DLR's A320 Advanced Technology Research Aircraft (ATRA) fitted with noise-abatement technologies pre-flight

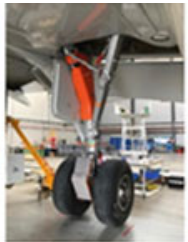

Brake covers and partial fairing on main landing gear (Safran LS)

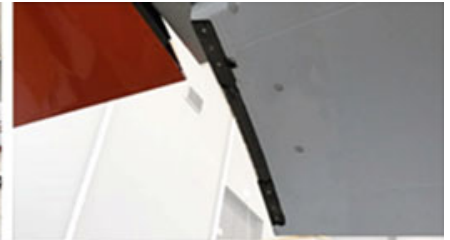

Porous Flap

Side Edge (Airbus)

Fig. 11 AFLONEXT key technologies 
Fan Noise: FLOCON investigated noise reduction concepts and associated devices able to reduce fan broadband noise from aero engines, conducting lab-scale experiments, complemented by numerical simulations to develop an understanding of the mechanisms involved and select the best concepts by balancing noise benefit and integration impact on a real aero-engine environment. Among promising technologies were an adaptive liner concept serving an overtip acoustic treatment as well as a rotor blade design with internal channels allowing to blow pressurised air through the rotor blades to fill their wake. Recently completed, the TurboNoiseBB project took over, enabling a major technical leap in providing the industry with low fan broadband noise concepts, based on an improved understanding of the broadband noise source mechanisms and validated broadband noise prediction methods. This included a new Outlet Guide Vane (OGV) design with leading edge serrations for broadband noise reduction and validation of an integrated 3D Aero/Mech/Noise design process. In terms of computational aeroacoustic methods, both LEE and DES simulations of rotor-stator stage progressed significantly (Fig. 12).

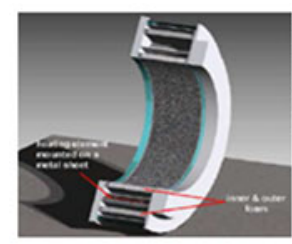

Impedance adaptive liner element as a tuneable overtip acoustic treatment

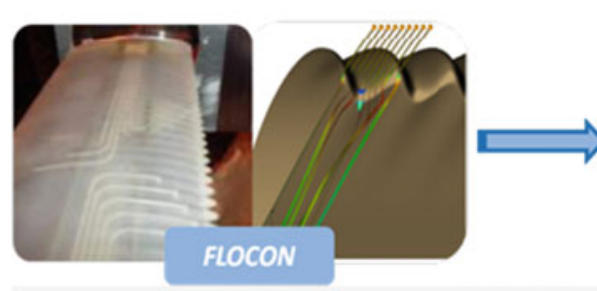

Rotor blade with internal channels
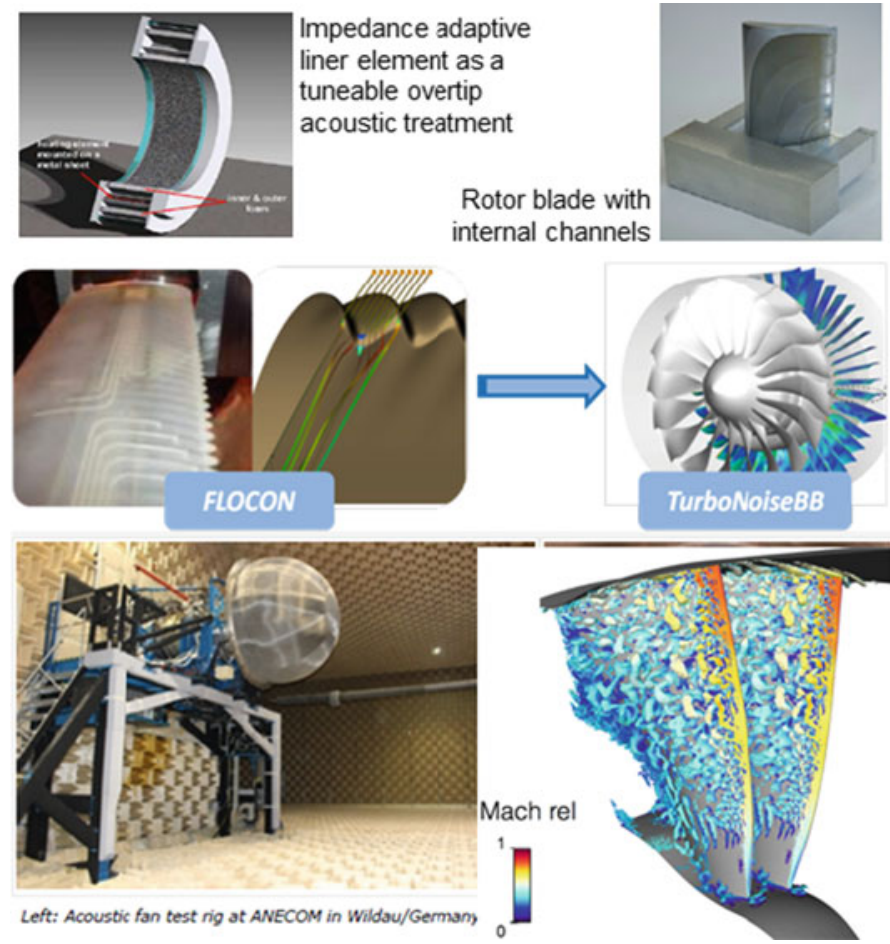

Fig. 12 Examples of FLOCON and TurboNoiseBB key features 

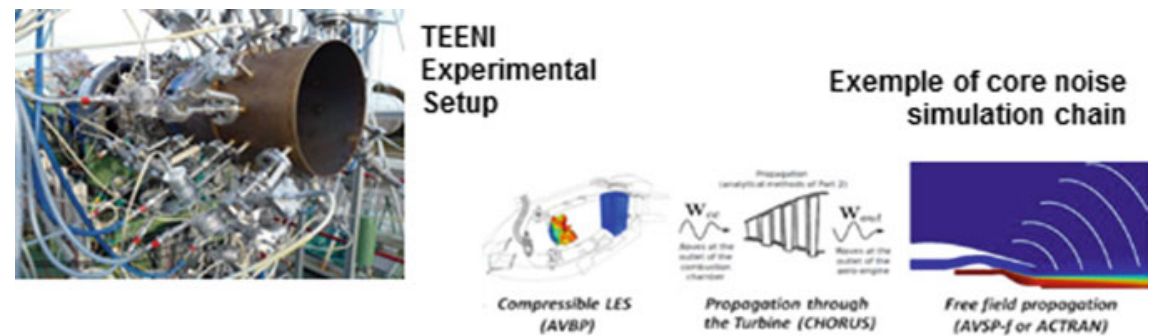

Fig. 13 Examples of TEENI and RECORD key features

Core Noise: The TEENI project dealt with experimental identification of engine core noise emission. Turboshaft exhaust noise is assumed to be a mix between combustion and turbine noise, with very little jet noise. It is representative of what is generally called core noise on aircraft engines. TEENI helped to provide further insight on this complex issue, thanks to a simpler geometry and absence of strong competing noise sources (such as jet and fan noise). Combustion noise was identified at low frequencies and its relative importance shown to be increased downstream of the High Pressure Turbine. In a complementary fashion, RECORD investigated the core noise generation mechanisms caused by the combustor and the combustorturbine interaction. Through development and validation of core noise prediction methods ranging from low order modelling approaches to high-fidelity compressible Large Eddy Simulation (LES). These methods were validated by different experimental test cases focusing on the different aspects concerning aerodynamics of the flow field, the combustion process and the flow conditions in a real turbine stage (Fig. 13).

Jet Noise: ORINOCO was one of the first projects co-funded by the European Commission and the Ministry of Industry and Trade of Russian Federation, dedicated to advanced jet noise control based on plasma actuators. The use of plasma actuators is a novel concept that required fundamental approaches to understand the interaction mechanisms with the main jet shear layer and the resulting radiated sound. Several plasma techniques were improved and developed.

Addressing another key jet noise related area, the JERONIMO project supported an improved understanding of the physical mechanisms of UHBR Engine s(BPR > 12) installed jet noise with jet-wing interaction, allowing to develop and validate Engine jet noise prediction processes based on anechoic Wind-Tunnel tests and numerical simulation (Fig. 14).

Airframe Noise: the VALIANT projects focused on broadband airframe noise modelling, tackling both landing gears and high lift devices, the two main contributors. Large Eddy Simulation-based approaches provided promising results, but emphasized the critical needs in terms of CPU and available memory for such types of calculations. Recommendations for simplification of design assumptions were made to address these issues considering current capability limitations (Fig. 15). 

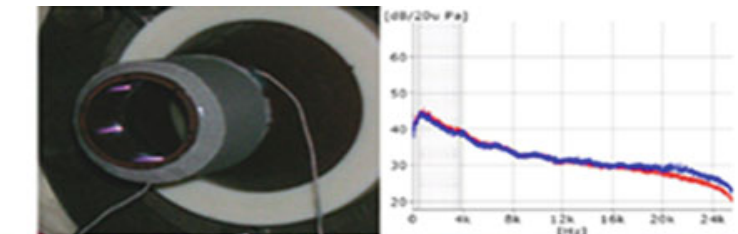

\section{Noise reduction}

(0.7 dB) in the far

field with High

Frequency

Dielectric Barrier

Discharge

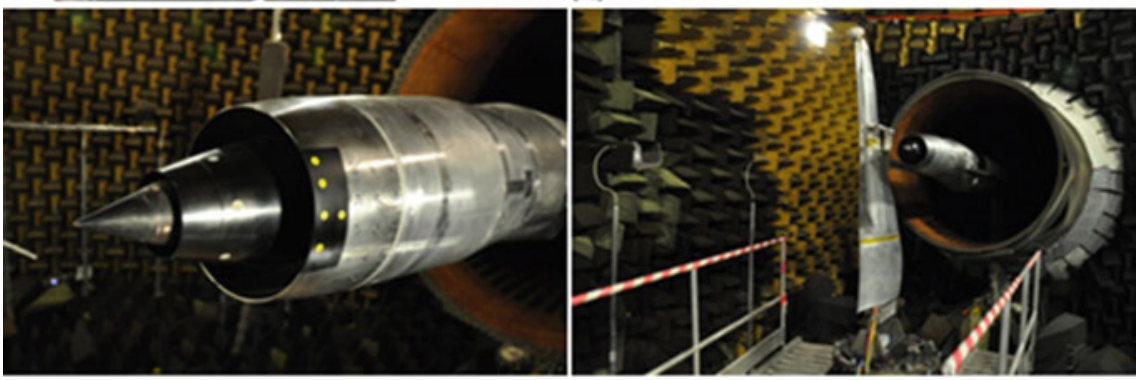

Installed UHBR exhaust system at CeprA19 anechoic wind tunnel

Fig. 14 Examples of ORINOCO and JERONIMO key features

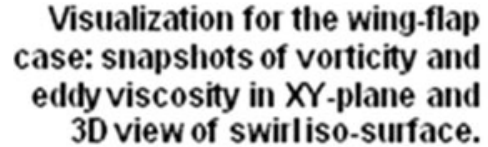

Visualization for the wing-flap eddy viscosity in XY-plane and 3D view of swirliso-surface.

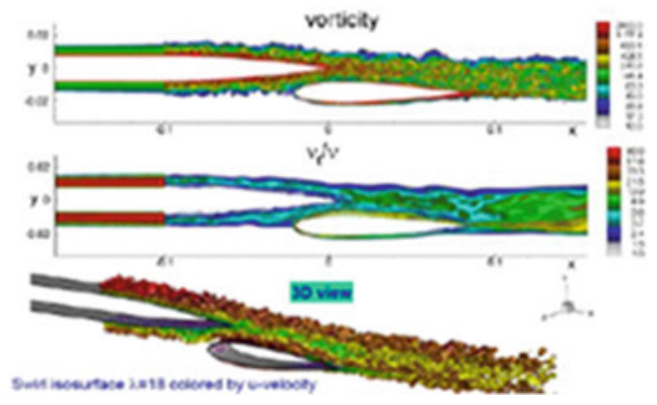

Fig. 15 Examples of ORINOCO and JERONIMO key features

Acoustic Liners: In the footsteps of advances registered in OPENAIR on advanced active liners, ENOVAL further supported the investigation of the electromagnetic concept based on electronically controlled areas of loudspeakers. In light of the new perspectives brought by the fast emergence of additive manufacturing capabilities, passive liners innovative concepts were also investigated by AERIALIST a project specifically addressing the use of meta-materials applied to the reduction of engine and airframe noise emission. This effort has been complemented by dedicated liner activities on-going within the frame of the larger ARTEM project, addressing innovative passive and adaptive liner concepts and their implementation issues relevant to the use of UHBR turbofans and distributed propulsion configurations (DEP) on future aircraft concepts (Fig. 16).

To build on such achievements and consolidate the anticipated noise benefits, a further effort is currently going on in two complementary directions: 

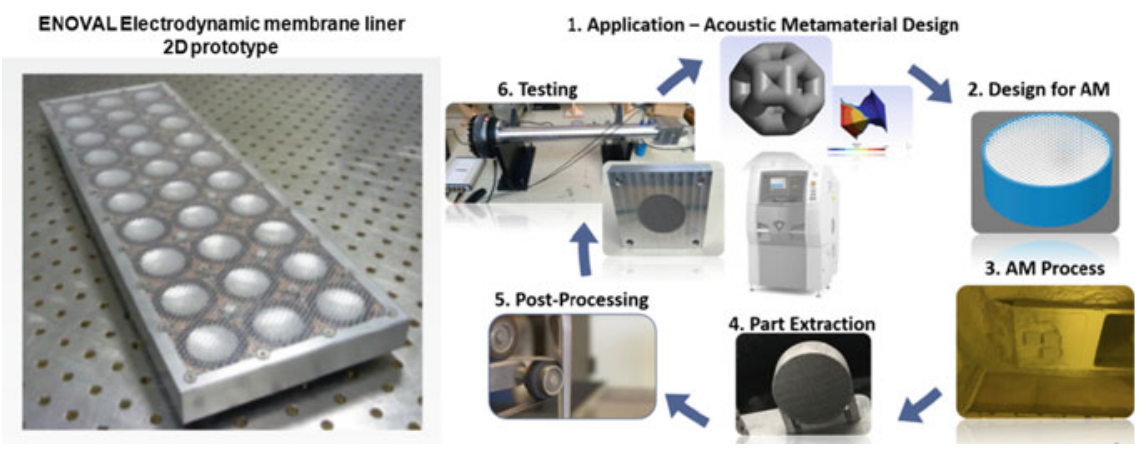

Fig. 16 Examples of ENOVAL and AERIALIST key features

(a) Pursuing the work on future advanced prediction techniques through 3 clustered projects launched in 2020:

- DJINN, which will develop a new generation of reliable computational fluid dynamics (CFD) methods to assess promising noise-reduction technologies for future integrated propulsion aircraft. Improved CFD methods for multi-physics modelling utilising high-performance computing are expected to reduce design times and costs by around $25 \%$ compared to large-scale testing.

- INVENTOR which will study the physics of noise generated by landing gears and high-lift devices to achieve further progress as airframe noise remain a major source of noise during landing operations.

- ENODISE which aims at reducing aircraft gaseous and noise emissions by improving the integration of the propulsion system with the airframe. To this end, it will investigate the existence of local/global integration optima via an innovative experimental methodology combined with reduced order modelling and machine learning strategies.

(b) Moving previous collaborative projects findings closer to industrial application, taking advantage of the CLEAN SKY 2 call for projects mechanism. As of the end of 2019, 16 noise related project involving 26 research partners had benefitted from such support. These aimed in particular at:

- Further integration of aeroacoustic design methods into industrial processes: Open Rotor Low Noise design (PROPMAT, SCONE), installed jet noise (INSPIRE) and core noise assessment (CIRRUS).

- Further maturation of advanced noise reduction technologies, taking on the promising active liner concept studied in ENOVAL (SALUTE) as well as several low noise OGV concepts first investigated in OPENAIR, FLOCON and TurboNoiseBB (INNOSTAT). Experimental evaluation on a fan rig will allow to compare these solutions and anticipate on industrial application issues (Figs. 17 and 18). 

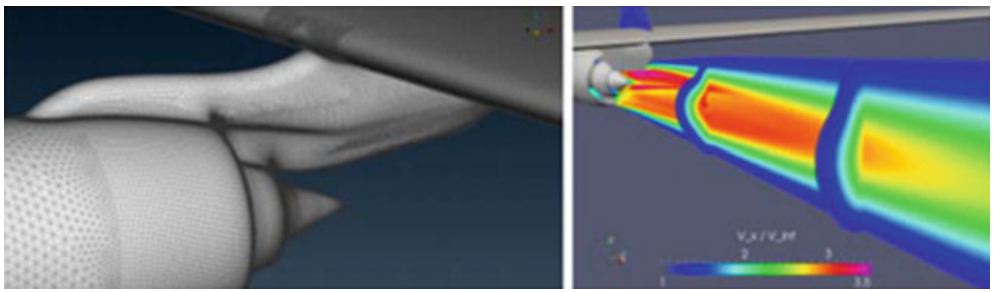

Fig. 17 Simulation of installed jet noise (INSPIRE)

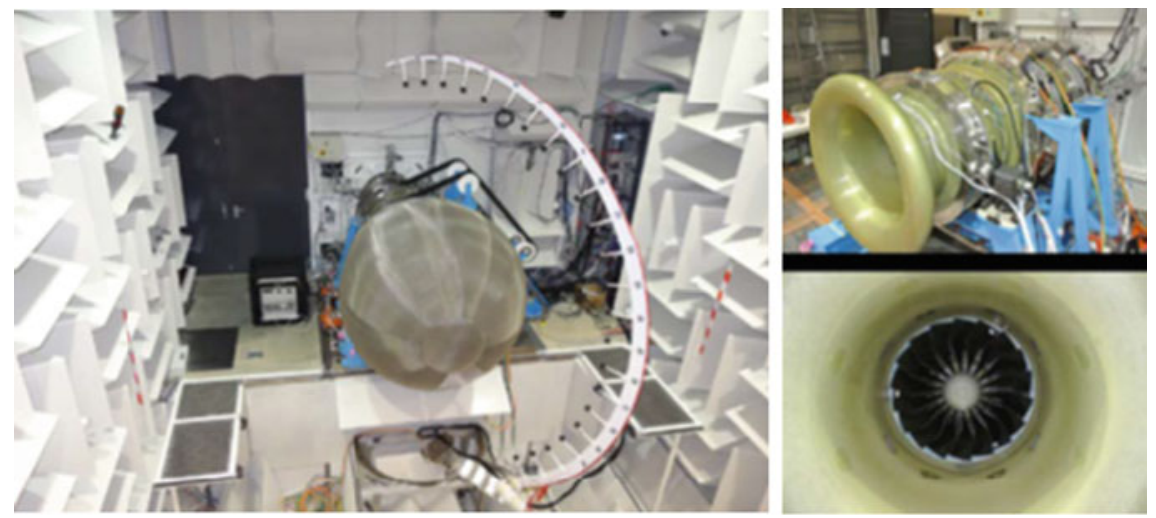

Acoustic liners and OGV design validation at PHARE acoustic test rig in Lyon

Fig. 18 Acoustic liners and OGV design validation at PHARE acoustic test rig in Lyon (SALUTE and INNOSTAT)

\section{Novel Propulsion Concepts and Airframe Configuration-Achievements and Perspectives}

Ultra High By-Pass Ratio (UHBR) engine Concept: Further noise reduction at source is expected to be provided by the availability of ultra-high by-pass ratio propulsion concepts (from 12:1 up to 20:1) fitted on aircraft applications with entry into service (EIS) from 2025 onwards. While leading to lower noise by design, the by-pass ration increase is anticipated to lead to additional weight and drag due to the increase of the fan diameter.

The overall target of the ENOVAL project was then to reduce $\mathrm{CO}_{2}$ emissions by up to $26 \%$ compared to the year 2000 reference engine, where the specific contribution of ENOVAL will be 3-5\%, while providing an incremental benefit up to $-1.3 \mathrm{~dB}$ on the way to the 2050 ACARE noise target (Fig. 19). These objectives have been enabled by addressing the following breakthroughs technologies, to be validated at component level up to TRL5: 


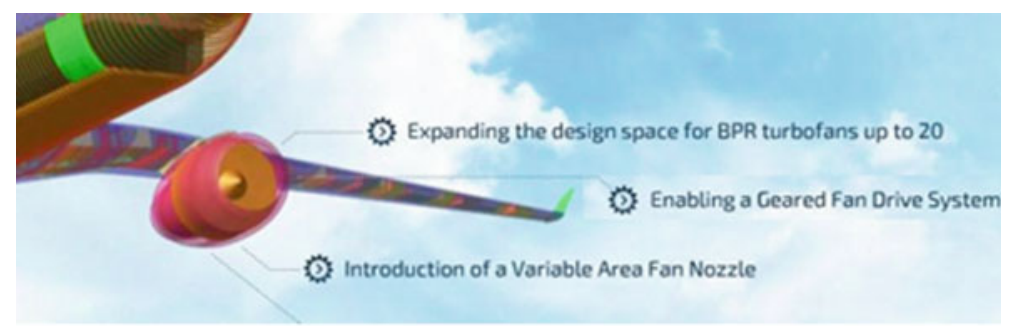

ENOVAL Key Technology Objectives for UHBR engines

Fig. 19 ENOVAL Key Technology Objectives for UHBR engines

- Expanding the design space for Turbofans up to BPR 20: Advanced Fan Blades, Light weight Intermediate Case, Holistic design concepts for shorter and thinner Nacelle with enhanced integration and acoustic liners, Improved LP-Turbine designs.

- Enabling a Geared Fan Drive System for the very large, long range engines

- Introducing a Variable Area Fan Nozzle (VAFN) for optimum stability and design for low pressure ratio fans

Other innovative UHBR options such as the counter rotating fan system were investigated in the COBRA project co-funded by the EU and the Russian Federation (see Fig. 20).

Counter-Rotating Open Rotor (CROR) engine concepts: CROR engine concepts have re-emerged in recent years as a serious option to provide the needed fuel burn benefits implied by the targets set for aviation $\mathrm{CO}_{2}$ emissions reduction. It is then per se a significant contributor to the ACARE $\mathrm{CO}_{2}$ reduction target, whilst not a key contributor to the achievements of ACARE noise target.
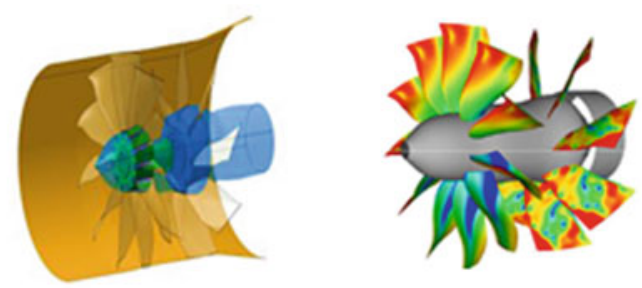

COBRA: Contrafan mechanical and noise design optimisation

Fig. 20 COBRA: Contrafan mechanical and noise design optimisation 
However, noise was considered as a major issue in the initial investigation effort of such engine concept, which culminated in a series of noise evaluation flight tests performed in the US in 1986-1987. As a consequence of this situation, a significant effort has been and still is dedicated to noise reduction as part of European research programmes dedicated to CROR engine concepts. Investigated areas encompass advanced aeroacoustic blade design methodologies, optimised engine geometry and cycle, advanced installation configurations, reduction of installation effects. Such technology solutions have been explored in projects such as DREAM and NACRE, then in CLEAN SKY, Further wind tunnel experiments carried out under CLEAN SKY 2 have helped to consolidate the assessment of noise levels expressed in the previous report while a full scale engine demonstrator ran to confirm the high interest in such propulsion concept. At this stage, based on results from model tests in anechoic wind tunnel (TRL4), CROR-powered aircraft with an EIS around 2030 can be expected to produce noise levels similar to those of turbofan-powered aircraft recently certified. When placed in perspective with the best expectations resulting from the original 1987 post flight-test assessment, this represent a typical $20 \mathrm{~dB}$ noise reduction on a cumulative basis, a spectacular achievement for the European research effort initiated in 2008 through the DREAM project (Fig. 21).

The noise benefits provided by novel aircraft configurations are considered as a key factor to meet the ACARE noise targets. In the shorter term, tail-mounted tube and wing concepts are expected to provide a typical $2 \mathrm{~dB}$ noise reduction through masking effects. In the longer term, wider options associated blended-wing body concepts such as embedded nacelles or distributed propulsion systems should also significantly contribute to further noise reduction.

\section{Cumulative margin vs ICAO Annex 16 Chapter 3, EPNdB}

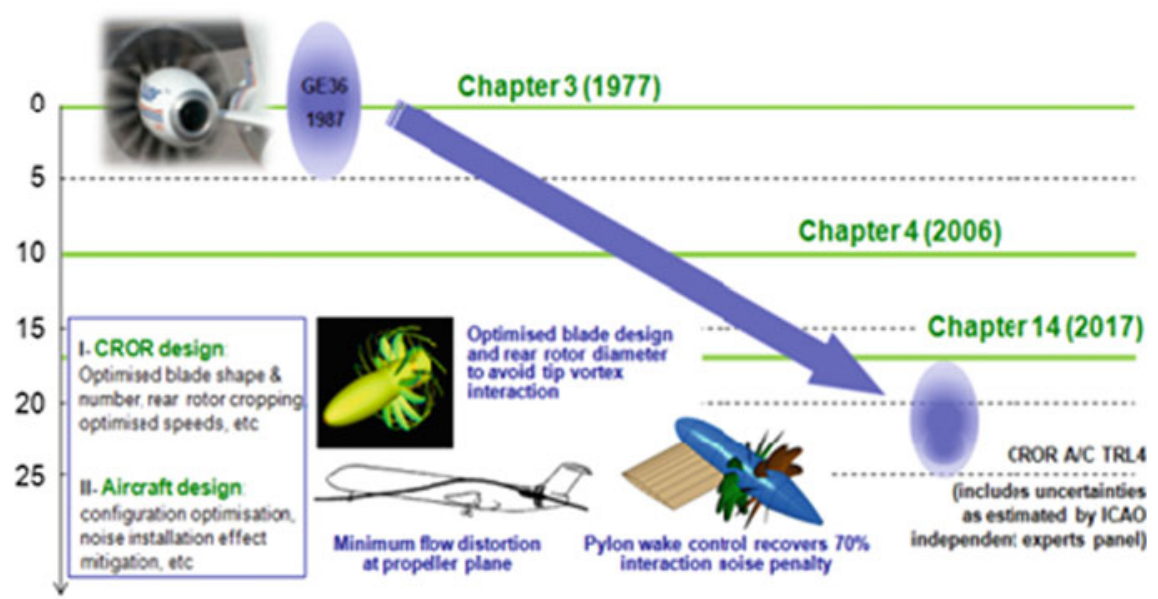

Fig. 21 Evolution of anticipated noise levels from CROR-powered aircraft 
Targeting the potential noise benefits expected from novel aircraft configurations, dedicated activity was initiated in ROSAS, then pursued in a multidisciplinary framework through the successful Framework 6 project NACRE which explored several new aircraft concepts tailored to address specific subsets of design drivers, including the Pro Green (PG) aircraft concept, paying major emphasis on the reduction of environmental impact of air travel.

Of interest for noise, key NACRE achievements included:

- Relevant work on Powered Tails and Advanced Wings for the Pro-Green concept, aiming at high environmental performance (noise and $\mathrm{CO}_{2}$ emissions): Contrafan and Open Rotor propulsion systems were integrated with a noise-shielding empennage and assessed (see Fig. 22).

- Progress on the understanding of the complex Flying Wing configurations, opening a new path for the promising over-body-engine configuration; Detailed aerodynamic and acoustic assessment of selected concepts were performed in particular for the over-the-buried 3-engine aircraft configuration.

- Tough not flight-tested yet, full development of the IEP concept into a demonstrator, establishing the foundations of a new kind of test facility in Europe based on real-atmosphere free flight and available for future projects (see Fig. 23)
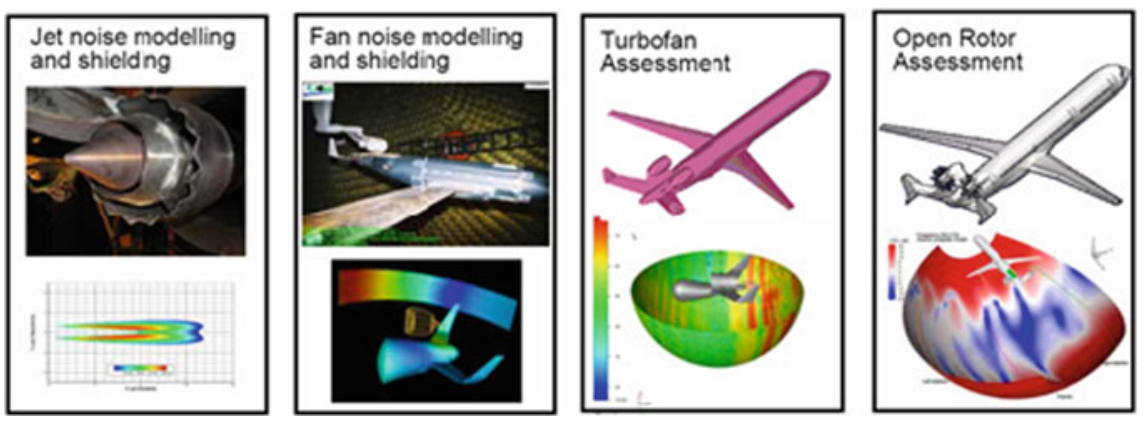

Fig. 22 Scope of NACRE activities on pro-green powered tail configurations


Fig. 23 Development steps of the IEP demonstrator 
Fig. 24 Noise shielding demonstrator

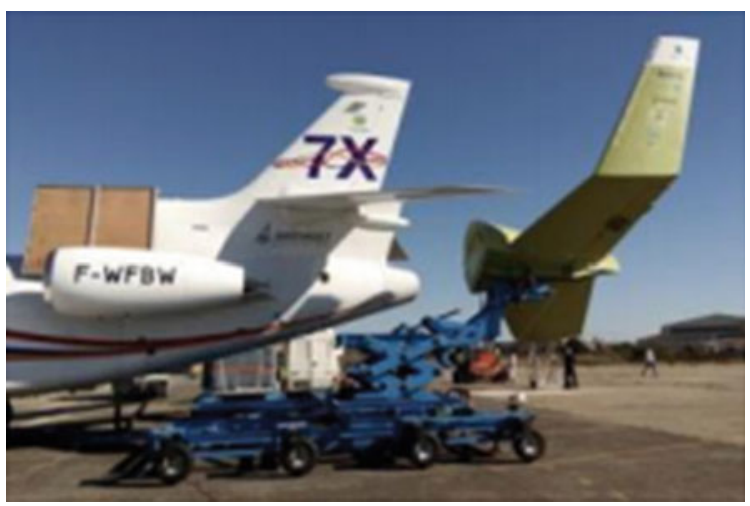

Innovative business jet aircraft architectures with an engine noise shielding afterbody were also investigated in CLEAN SKY. Noise assessments was performed using prediction tools and validated and calibrated using dedicated wind tunnel and static tests (see Fig. 24).

With regard to the longer term agenda, an active novel aircraft architectures effort is now underway supported through CLEAN SKY 2 as well as the PARSIFAL and ARTEM projects involving both innovative aircraft designs and advanced low emissions propulsion concepts such Boundary Layer Ingestion (BLI), Blended Wing Body (BWB) or Distributed Electric Propulsion (DEP). Boxwing/Prandtl Plane concepts should also provide noise reduction through optimised installation of the propulsion system. Figures 25 and 26 provide an overview of such installation concepts covered by ARTEM and PARSIFAL. The noise reduction expected from such designs is covered into the next Chapter.

\section{Noise Abatement Procedures (NAP)_Achievements and Perspectives}

As an integral element of the solutions to achieve the first 2020 ACARE target (50\% noise reduction), work on noise abatement procedures have progressed steadily over the years addressing the successive steps towards maturity:

- Develop flight trajectory concepts minimising noise impact

- Develop robust aircraft flight management capabilities

- Enable optimum implementation into Traffic Management Area.

At research level, noise abatement operational concepts have been involved in the following projects: 


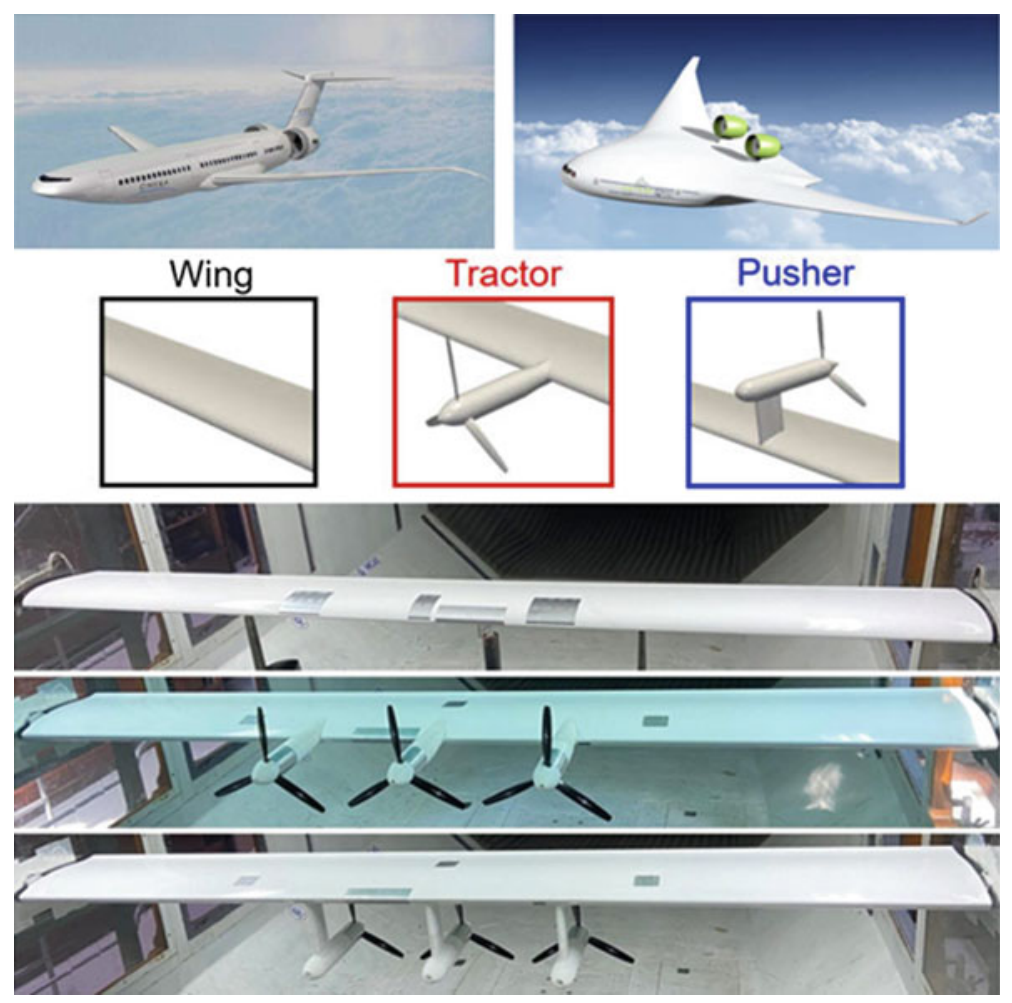

Fig. 25 Installation concepts studied in ARTEM

(a)



(b)

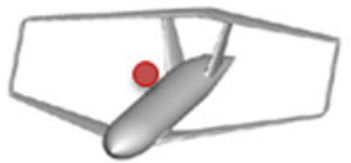

(c)

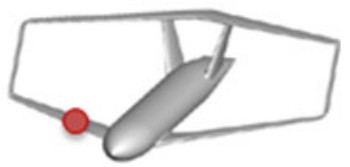

Considered engine locations: (a) under rear-wing location, (b) rear fuselage location and (c) above front-wing location. The engine acoustic source is represented by the red dot.

Fig. 26 Installation concepts studied in PARSIFAL

Departure.

- Optimised Noise Abatement Departure Procedures Sourdine

- Automated Management of optimized NADPs Sourdine 2

- Multi Criteria Departure Procedures CLEANSKY (SGO) (see Fig. 26) 
Optimization of a Noise Abatement Departure Procedure (NADP), with multiple criteria $\rightarrow$ Multi-Criteria Departure Procedure (MCDP)

$\rightarrow$ Optimization of the Vertical profile. The lateral route is imposed

$\rightarrow$ NADP begins at $35 \mathrm{ft}$ and finishes at the en-route configuration (start of climb)

Thrust: Take Off Rating $\rightarrow$ Intermediate Rating

Speed: V3Sft+DV2

Intermediate Acceleration

$\rightarrow$ Climb Rating

$\rightarrow$ En-route Speed xascous citilogoght

$\rightarrow$ Optimisation Parameters

- Zpr : Thrust Cutback Altitude

- N1 wen: Reduced Engine Rating

- Zpa : Acceleration Altitude

- Vmas : Intermediate Speed Target

- Zpf : Setting of Climb Rating and Start of Acceleration to En-route Speed

- $\Delta V 2$ : fraction of speed at 35ft in excess of safety minimum (V2)

Fig. 27 Multi criteria departure procedures

Arrival

Steeper approach

- Adaptive Increased Glide Slope (A-IGS)CLEANSKY (SGO) (see Fig. 27)

- Adaptive Runway Aiming PointCLEANSKY (SGO)

Continuous Descent Operations

- Fully Managed CDO OPTIMAL

- Adaptive Flight Path Angle SESAR.

In the most recent effort, as part of the CLEAN SKY activity, new approaches for the Management of Trajectory and Mission were addressed through the following concepts (Fig. 28):

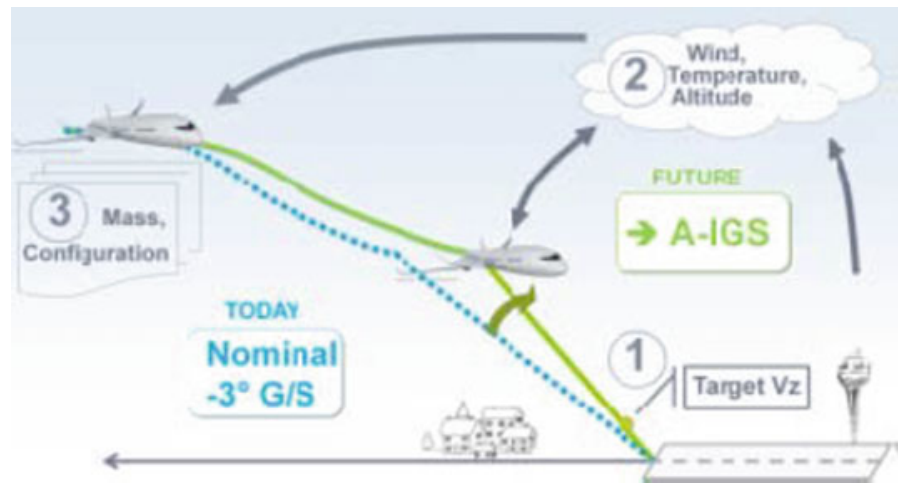

Fig. 28 Arrival adaptive increased glide slope (A-IGS) 


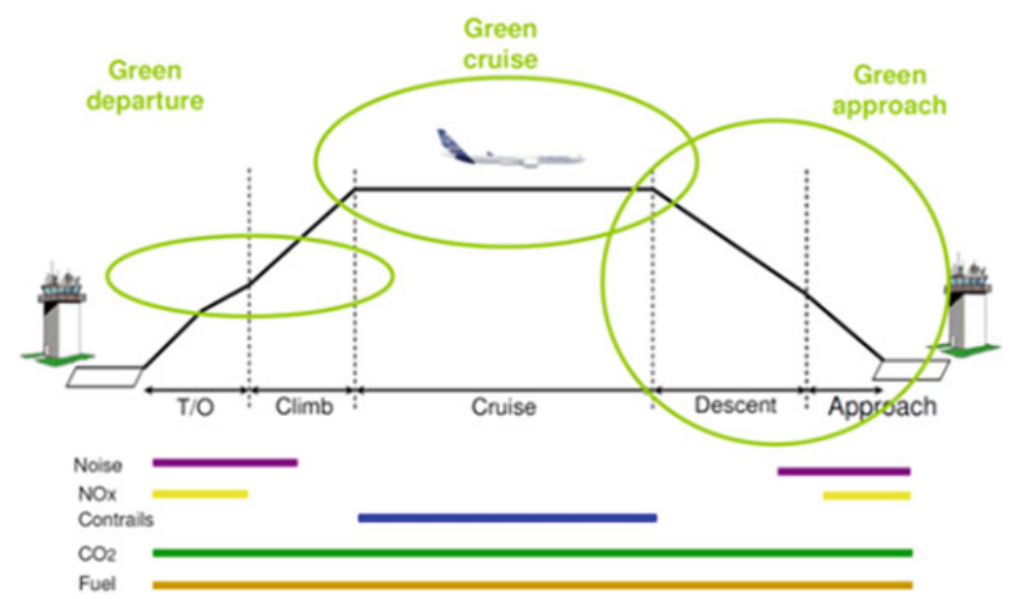

Fig. 29 Trajectory optimisation in 3 phases

- Green Trajectories, based on more precise, reliable and predictable 3 dimensional flightpaths, optimised for minimum noise impact and low emissions, including agile trajectory management, in response to meteorological hazard.

- A Green Mission from start to finish, with management of revised climb, cruise and descent profiles, which permit multiple criteria optimisation (especially of noise, emissions, fuel, time); including management for weather conditions, which could negatively impact the aircraft optimum route and result in additional fuel consumption.

Based on the results from several previous studies (e.g., OPTIMAL, FLYSAFE, etc.) these concepts needed to be enabled by the development of flight management systems (FMS) and guidance algorithms to provide high accuracy flight path prediction and control, encompassing flight phases (see Fig. 29):

- During departure and climb, the developed functions ensures a combined optimisation of $\mathrm{CO}_{2}$, noise and $\mathrm{NO}_{\mathrm{x}}$ emissions, meeting the constraints of each mission (including airport procedures, atmospheric conditions, aircraft state, etc.).

- During climb, the crew is able to optimise the vertical and lateral trajectory according to aircraft performance and weather conditions (mainly in respect of wind).

- In descent and approach phase, enhancements to the already studied CDA concept (from, e.g.,) are available, in order to enable CDA to be achieved even in dense traffic situations. 


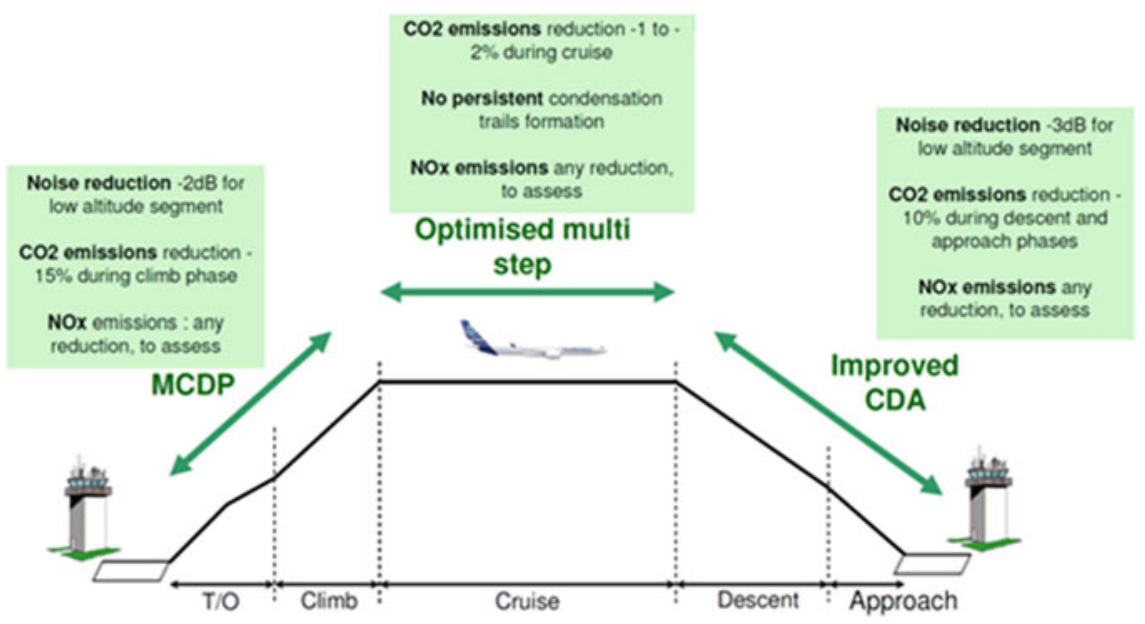

Fig. 30 FMS green functions: green objectives

Mission optimisation systems provide capabilities to build complete flight profiles optimised for multiple criteria including environmental impacts, combining selected climb, cruise and descent trajectories. This also encompasses the accurate real-time prediction of the complete flight profile and of its environmental impacts. The new functions are to be ultimately be integrated into the target product: the green FMS and demonstrated in cockpit simulations (see Fig. 30).

\section{Improvement in the Understanding of Aircraft Noise and Its Impacts}

While a significant effort was directed towards the achievement of the $-10 \mathrm{~dB}$ per operation target, a second noise objective defined by the ACARE SRA aims at ensuring that such benefit from technology and operational solutions effectively leads to there being no impacted people outside airport boundaries, provided the appropriate practices and policies are in place. Pan-European research activities were then initiated in the area related to Management of Noise Impacts. Three projects stand out in direct relation with the possible evolution of aircraft technical characteristics, along the following lines:

- How can the evolution of aircraft noise signature at takeoff and landing can positively affect impacts felt by surrounding communities (COSMA)?

- How to evaluate the noise impact of Open Rotor driven aircraft during cruise operations over ground (NINHA)?

- How to evaluate the impact of supersonic transport sonic boom phase on populations (RUMBLE)? 


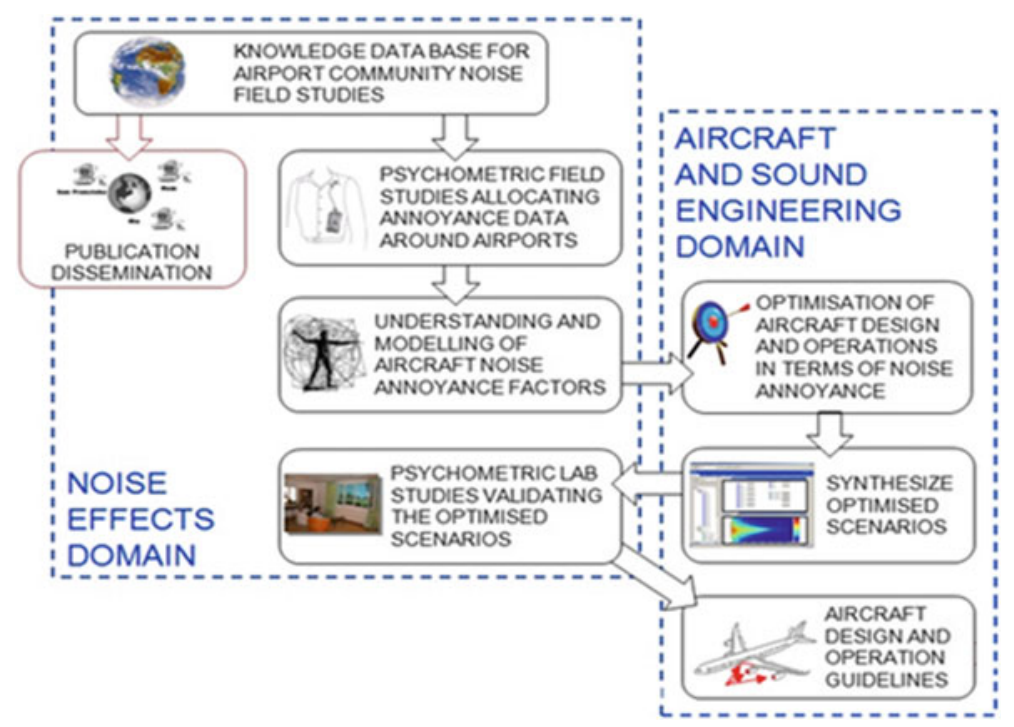

Fig. 31 COSMA multidisciplinary approach to establishing low annoyance criteria for aircraft operations

In this area, international collaboration has been very much in the picture, results from COSMA and NINHA were shared with US counterparts in dedicated workshops in view of involving cooperation with follow-up research efforts while Russia has been directly involved in the RUMBLE project activities from the beginning.

Supported by a well-balanced partnership, COSMA established a unique approach to aviation noise research, targeting significant progress in the understanding of community noise impacts while consolidating the relationship between the technology optimisation process and how the resulting aircraft sound is perceived (see Fig. 31).

COSMA's scientific concept led to innovative ways of combining sound engineering and noise effects analysis to generate low noise impact design recommendations for future aircraft. Extensive field studies around European airports, combined with psychometric laboratory studies formed the basis to establish optimal aircraft noise characteristics regarding lower annoyance. Specific sound synthesis techniques developed within COSMA re-created a realistic simulation of global airport operations and were then applied to the optimisation of flight procedures when associated with anticipated technology benefits.

Beyond its scientific results, COSMA is also leaving a legacy of harmonised test protocols and innovative simulation tools for future projects to use in improving the understanding of aviation noise effects. 
NINHA specifically addressed the noise impact of aircraft with novel engine configurations in high altitude operations. The potential introduction of aircraft fitted with advanced counter-rotating open rotor (CROR) engine power plants should contribute significantly to the reduction of fuel burn and gaseous emissions. In the 1980 s, prototypes of the first generation of open rotor engines were developed and tested. It was found that the noise generated by these engines, even in the en-route flight phase, could be considered significant, thus questioning public acceptance. Since then significant effort has been dedicated to improving the CROR aero-acoustic design, with promising results, as discussed earlier in this chapter.

The NINHA project re-assessed whether noise issues away from airports (i.e. during mid- to high-altitude operations, hereafter called "en-route") might potentially hinder the introduction of this new generation of power plant. The project was organized around 3 main challenges: (1) Adapt existing models for long-range propagation and validate them, (2) Predict noise levels on ground generated by CROR enroute, (3) Assess ground noise impact of CROR relative to conventional powerplant, including turboprops. A groundbreaking step was the validation of the long-range propagation model by means of a dedicated flight test performed on the A400M (see Fig. 32).

Based on improved long-range propagation models and 2012 CROR technology capabilities, an updated vision statement on en-route noise levels of CROR configurations was put in perspective with respect to initial efforts carried out around 1986-1988 by NASA and the industry. The NINHA project then established that at cruise the noise of CROR engines with today's technology will be significantly reduced from that of the UnDucted Fan of the 1980s, the maximum noise level being equivalent to that of today's Turbo-Propeller driven aircraft in cruise condition.
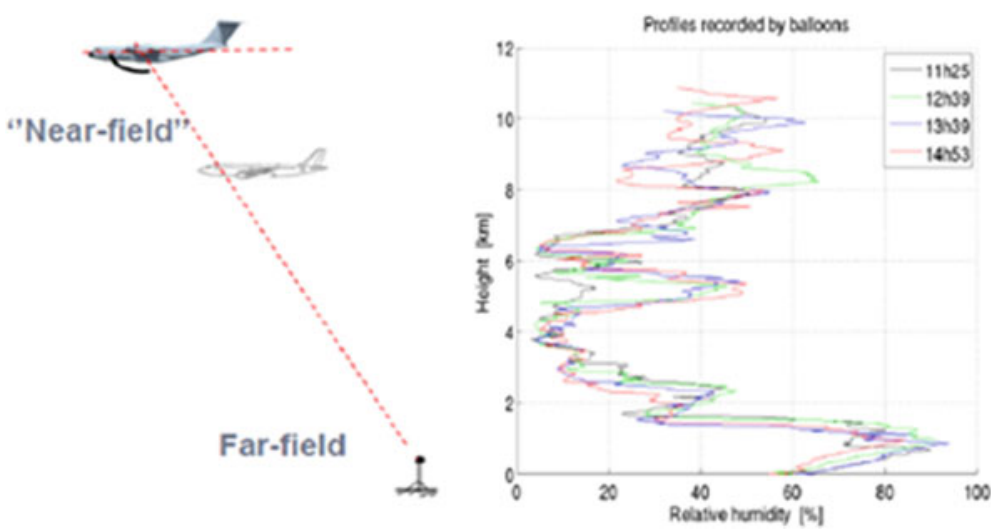

Fig. 32 Overview of NINHA flight test set-up to validate long distance noise propagation models 


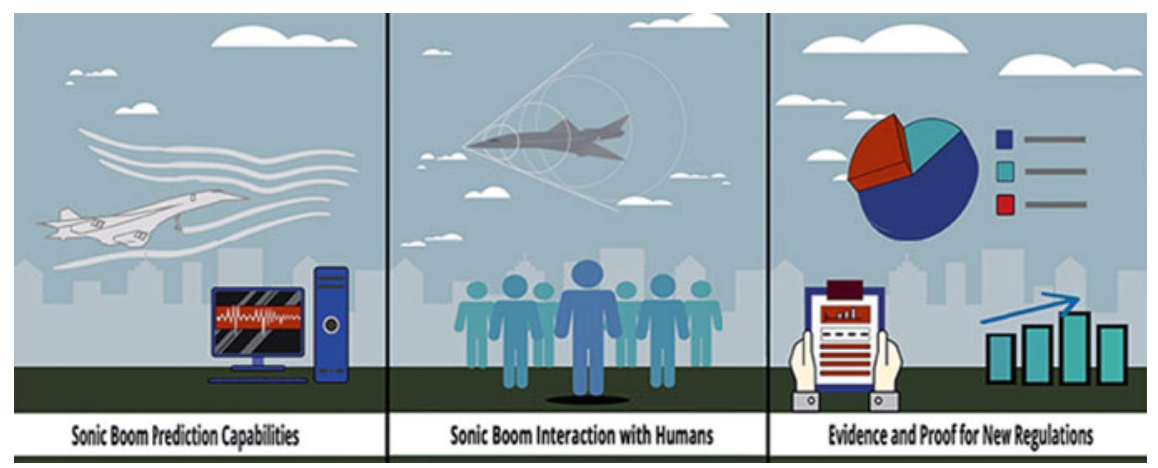

Fig. 33 Scope of RUMBLE activities

Impacts-oriented activities are also complemented by RUMBLE, which currently addresses the en-route noise produced by supersonic civil aircraft. As such, it aims at producing the scientific evidence requested by national, European and international regulation authorities to determine the acceptable level of overland sonic booms and the appropriate ways to comply with it (see Fig. 33).

Another issue is directly associated with supersonic aircraft is the capability to manage landing and takeoff noise levels compatible with subsonic aircraft standards, and if not the case to identify the level of acceptability in the general public for such operations, even limited in number. The recently launched SENECA project is related to a clear need to clarify such questions marks, as expressed by regulatory bodies.

The need to consider a wider and more global effort on aviation noise impacts was at last addressed through the ANIMA project.

As exposed earlier in the "Phased Strategy" section, it was recommended that, in order to exploit new technology and low noise operations developments and to enable integrated impact mitigation solutions, a dedicated effort would need to:

- improve and continuously update the understanding of how noise from air transport operations implemented through new Air Traffic Management solutions affects people

- provide the technical support to successful implementation of planning policies compatible with traffic growth for the long term benefit of the communities

This also included Enabling Factors such as tools supporting transparent communication policies covering relevant indices, flight path / operations on-line forecast and tracking as well as comprehensive assessment of environmental interdependencies and monetisation of impacts. 
Implementing such longer term recommendations further, ANIMA addresses key aspects of noise effects and impacts in:

- carrying out a critical review and assessment of noise impacts and existing management practices to establish best practices' guidelines for an effective management of annoyance beyond ICAO Balanced Approach

- developing a better understanding to address community annoyance, sleep disturbance and improve quality of life

- developing Noise Management Toolset to empower non-specialists with decision support capability

- testing and validating with end-users (airports and community) an "Aviation noise community platform", gathering tools and best practices, facilitating consensus building and engaging communities in the mitigation process, ensuring exploitation of the results.

Achievements from the ANIMA project are presented in detail in several chapters of this book.

\section{Assessment of Progress Relative to ACARE Noise Reduction Targets}

At this stage, three formal evaluations relative to the 2020 ACARE targets have been performed in succession (AGAPE-2011,OPTI-2013, X-NOISE/ACARE-2015) while a new assessment is close to completion relative to the final position on 2020 targets as well as a first vision of progress relative to 2050 goals. These efforts are described in the following sections.

\section{Background and Methodology}

The initial SRA1 approach presided over the definition of the ACARE 2020 noise targets, as originally based on the Balanced Approach concept developed by ICAO:

- The first noise target aims at reducing noise emission of flying vehicles by half, which was translated in quantitative terms as an average reduction of 10 decibels per operation, taking into account both technology benefits and operational improvements.

- The second noise target aims at ensuring that the $10 \mathrm{~dB}$ benefit in noise emission anticipated for fixed-wing aircraft effectively leads to there being no impacted people outside airport boundaries, provided the appropriate management practices are in place. For the sake of evaluation, this was translated in quantitative terms to a 65 Lden target at airport boundaries. 
The first two elements of the Balanced Approach concept (noise reduction at source, noise abatement procedures) constitute the identified contributors to the $10 \mathrm{~dB}$ reduction aircraft noise target, and can be further described in terms of associated technical and operational solutions as shown below:

- Quiet Aircraft contributor associated solutions: Noise Reduction Technologies (NRT) generation 1 and 2, Novel aircraft and engine/powerplant architectures

- Noise Abatement Procedures contributor associated solutions: Improved Operating Practices with Current Concepts / Optimized Operations with New Technology/ATM-ATC Integration.

In the course of previous formal progress assessment exercises (AGAPE, OPTI), a methodology for the evaluation of progress has been established within the noise community, based on two complementary tools described below.

Firstly, the internationally recognized TRL scale, that enables keeping track of the situation of individual technologies identified in the SRA1as key elements of the ACARE technology-oriented solutions for noise reduction. This tool is being used to measure the progress in term of strategy implementation considering the initial technology panel promoted in the SRA1.

Secondly, on a dedicated Aircraft Noise Technology Evaluation (ANTE) process, involving a predictive model with the capability to roll up the benefits of individual technologies at solution level for a number of current and advanced aircraft engine configurations. This tool is being used to establish quantitatively the progress achieved at solution level as well as overall versus ACARE targets, including operational aspects, when applied to a typical airport platform in 2020. Initiated via the SILENCE(R) project, it has been implemented since 2001 through the string of major EU projects dealing with aircraft noise reduction.

Thus, in the following pages, the TRL status will be mostly used to support the expert group qualitative analysis in terms of assessing the implementation of the initial SRA1 strategy, evaluating the size of the associated effort and identifying potential gaps emerging from either technical difficulties or insufficient funding support or new priorities and technological avenues. In parallel, the existing Technology Evaluator exercises will support the quantitative analysis of achievement relative to the ACARE targets.

Figures 34 and 35 summarise the selected methodological approach, fully applicable to the primary aircraft noise target described in the SRA1, i.e., $10 \mathrm{~dB}$ reduction per aircraft operation.

As hinted at on the noise effort projects roadmap (Fig. 7), the status of research progress concerning technology and operational solutions can be assessed concentrating on the results achieved by larger projects. These full-scale demonstrator projects exploit the upstream research achievements of smaller projects carried out at EU or national level. The resulting solutions at TRL 6 level allow industry efforts to take over further maturation dealing with key industrial application issues. 


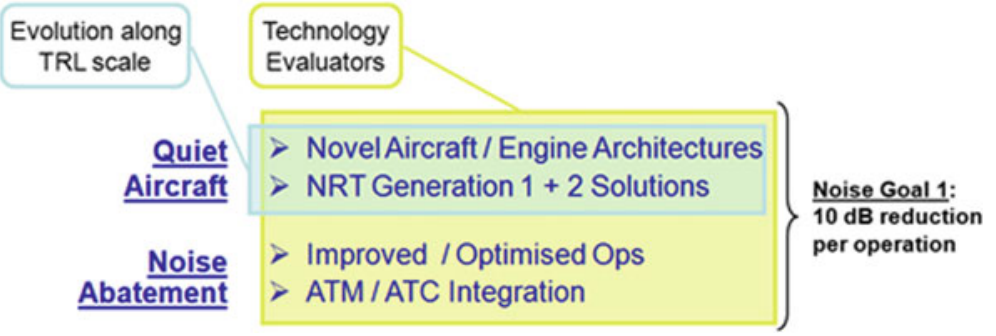

Fig. 34 Tools aimed at noise target evaluation for fixed wing aircraft

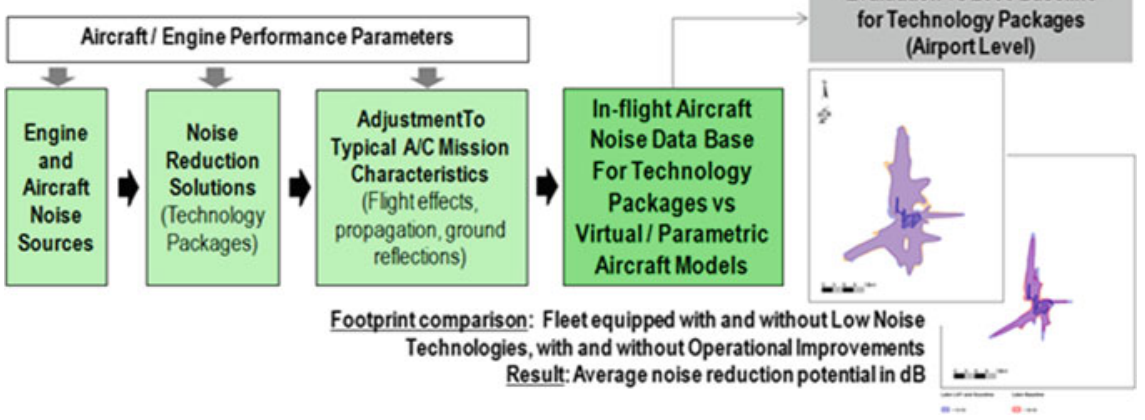

Fig. 35 Aircraft noise technology evaluation (ANTE) process

The dedicated technology evaluation methodology has been implemented in such large key projects to evaluate and provide a measure of anticipated achievements at TRL6 level, consistent with the ACARE framework and objectives established for 2020. The previous AGAPE and OPTI assessments relied then on the results of OPTIMAL, SILENCE(R), and VITAL confirming that TRL6 solutions (NRT Generation $1+$ Noise Abatement Procedures (NAPs), ) supported the achievement of the mid-term target of $-5 \mathrm{~dB}$ per operation. In dealing with the further steps towards the $-10 \mathrm{~dB}$ target (NRT Generation 2, Novel Architectures), the 2015 assessment exercise benefited from the achievements of the OPENAIR project as well as interim results from CLEAN SKY in specific areas related to business jets and regional aircraft in particular. 


\section{Changing Boundary Conditions}

The initial recommended approach presiding over the definition of the ACARE 2020 noise targets remains valid, as originally based on the general Balanced Approach concept developed by ICAO. The first two elements of the concept (noise reduction at source, noise abatement procedures) constitute, in practice, the identified contributors to the $10 \mathrm{~dB}$ reduction aircraft noise target.

However, a number of external factors are worth mentioning, as further developed below. When the SRA1 was established, environmental targets (Noise, $\mathrm{NO}_{\mathrm{x}}, \mathrm{CO}_{2}$ ) were established in parallel without considering possible interdependencies, either at technology or operational level. Historically, the industry has had to comply with standards set in ICAO for noise and $\mathrm{NO}_{\mathrm{x}}$. It has been the industry's ability to reduce these effects, whilst at the same time for the benefit of operators improving fuel efficiency, that has allowed aviation to grow rapidly in recent years without losing general public support. However, aviation more recently faces two important shifts. First, there is an increasing focus on climate change as a key environmental issue, indeed the dominant one for some stakeholders, leading to a new $\mathrm{CO}_{2}$ standard soon to be established by ICAO. Second, as a result of the potential introduction of new technologies, there may be a need for stakeholders to make more explicit choices about which environmental effects to prioritise. Broadly, it is likely that in future generations of aircraft, manufacturers will have the option to pursue incremental developments on current technology. It is suggested that this could deliver substantial reductions in noise and improvements in fuel efficiency, which although worthwhile are not in the same order of magnitude. An alternative would be the use of technology such as open rotor engines for narrowbody aircraft, which could deliver large improvements in fuel efficiency, while achieving less progress on noise reduction.

In parallel with this evolution driven by global environmental issues, there is evidence of increased sensitivity to noise in local communities impacted by aviation operations despite significant reduction of aircraft source noise over the years. The air transport growth perspectives in Europe then remain conditioned to improvements in all three elements of the Balanced Approach. As proposed as part of the SRIA 2050 Volume 2 airport noise section, it is essential that a greatly increased effort is launched to address the key aspects of noise effects and impacts and ultimately to support the implementation of successful policies complementing the technological achievements expected to be realised.

These different aspects have been considered in performing the progress assessment reported in the following sections and in formulating associated recommendations for future research. 


\section{Progress Assessment}

The 2015 progress assessment exercise was performed within the framework of the XNOISE EV project at ACARE's request. An approach by consensus based on experts judgement, assessment of the TRL situation and results from the technology evaluation exercises was used, coming up with updated progress achievement figures and formulating associated recommendations for future research. The exercise findings are summarised below.

Since the year 2000 a number of civil air transport aircraft have been certified by the European industry. The 2015 situation provided a representative panel of effective implementation of state-of-the-art Generation 1 Noise Reduction Technologies (NRT) delivered to TRL6 by completed research programmes such as SILENCE(R) and VITAL. The observed average achievement, together with $2 \mathrm{~dB}$ operational benefits of noise abatement procedures, was totalling $5 \mathrm{~dB}$ of the ACARE target, as shown in Fig. 3.

In dealing with the further steps towards the $-10 \mathrm{~dB}$ target (NRT Generation 2, Novel Architectures), the 2015 assessment exercise benefited from the achievements of the OPENAIR project as well as interim results from CLEAN SKY in specific areas related to business jets and regional aircraft, in particular.

At the end of the OPENAIR project, 15 “Generation 2" Noise Reduction Technologies achieved TRL 4/5 through large scale testing in wind tunnels and/or dedicated engine fan or exhaust rigs. These technologies were aimed primarily at Short-Medium Range and Long-Range aircraft fitted with advanced ducted turbofans. Through CLEAN SKY, additional efforts reached similar TRL achievements on complementary noise reduction solutions aimed at Regional Aircraft (low noise landing gear and highlift devices) and Business Jets (U-Tail). In addition to technology solutions, CLEAN SKY also brought further consolidation of noise abatement procedures benefits. Finally, CLEAN SKY produced a first noise evaluation of the Contra Rotating Open Rotor (CROR) engine concept at mission level on a Short-Medium Range aircraft.

When combining the CLEAN SKY interim analysis (2014) with the OPENAIR final analysis at airport level and considering the relative importance of business and regional operations, it was concluded that a typical $2.5 \mathrm{~dB}$ additional benefit, relative to the $5 \mathrm{~dB}$ already consolidated at TRL 6, can be expected from Generation 2 Noise Reduction Technologies provided such technologies mature to TRL6 in time for 2020. The combined CLEAN SKY/SESAR effort on low noise abatement procedures was also expected to provide further consolidation towards TRL6 of the $2 \mathrm{~dB}$ benefit registered earlier.

These findings have then been implemented into the ACARE general indicator established to provide a measure of overall achievement relative to a given 2020 target.

Five years ahead of 2020, the progress registered since 2000 was considered significant, reaching an excellent level of completion with about $64 \%$ of expected 
benefits secured, due to effective implementation of the research roadmap and associated priorities. In terms of identified contributors, the investigation and development of recommended ACARE solutions have been well supported at European level over the years, complemented by a steady activity at national level.

Relative to the second ACARE 2020 noise target (number of people impacted outside airport boundaries), a pilot study led to the following observations:

- Benefits of each individual element differ significantly (very airport dependent)

- The effect of Land Use Planning may be of the same order of magnitude as that of noise reduction at source

- A combination of the two actions above are required to maintain the future population affected below 2000 levels.

The full assessment process, however, will require a very significant amount of input information and need effective support, if it is to be in place and validated ahead of the next assessment exercise. In the meantime, dedicated research actions should address the development of updated dose-response relationships to allow a translation from exposure (in terms of Day-evening-night equivalent level (Lden)) to annoyance suited to the characteristics of today's and tomorrow's operations.

Considering the evidence of increased sensitivity to noise in local communities impacted by aviation operations, it is, in fact, essential that a greatly increased effort is launched at the earliest opportunity to address the key aspects of noise effects and impacts and ultimately support the implementation of successful policies complementing the technological achievements expected to be realised. A strongly coordinated and integrated approach would definitely provide a significant added value relative to the business as usual (BAU) approach currently generally prevailing in Europe in this area of noise impacts.

\section{Recent Developments in Assessing ACARE 2020 and 2050 Noise Targets and Associated Recommendations}

In 2020, ACARE WG3 has undertaken an exercise to determine the progress towards the ACARE goals, looking at both the ACARE 2020 as well as the ACARE 2050 goal. A group of experts from industry, Eurocontrol and airlines have gathered material to support the assessment which has resulted in a draft report within ACARE, expected to be used in a future publication.

In Section "Background and Methodology", the ACARE 2020 goals translation into quantitative terms has already been discussed. Similarly, for the ACARE 2050 goal we can translate the 2050 noise goals of reducing the perceived noise by $65 \%$ (relative to the year 2000), as average reduction of 15 decibels per operation, taking into account both technology benefits and operational improvements.

This reduction has been defined as the TRL6 technology readiness level. 
For the 2020 assessment, the experts used the XNoise led 2015 assessment as a starting point and evaluated the 2015-2020 timeframe. During this period, the AFLONEXT project was the only project that brought additional noise technologies to TRL6 trough full scale flight testing. However, as there was no evaluation at aircraft/fleet level, the contribution to the ACARE goals could not be quantified for this project.

Several noise research efforts between 2015 and 2020 changed focus towards novel configurations. On aircraft configurations, the ARTEM project made progress and on engine configurations, the Open Rotor engine required significant research. The traditionally noisy unducted engine architecture, forced resources to support several wind tunnel campaigns to bring innovative noise solutions for a society demanding low $\mathrm{CO}_{2}$ transport.

For the $10 \mathrm{~dB}$ goal of ACARE 2020, the latest overall Technology evaluation assessment, combined with engineering judgement on the benefits from Noise reduction at the source and Noise Abatement Procedures were assessed to have progressed by $6,4 \mathrm{~dB}$. This means that, with a gap of $3.6 \mathrm{~dB}$, this ACARE 2020 goal has NOT been achieved.

With respect to the 2nd ACARE 2020 noise goal related to the elimination of nuisance outside airport boundaries, quieter aircraft have entered the fleet since 2000. However, the number of annoyed people within the noise contours has increased from 2005 to 2017 by about $10 \%$ (ref EASA Environmental report 2019). This means that this ACARE 2020 goal has NOT been achieved.

To determine whether we are on track for the 2050 goal, the experts took a look into the advancement in time. They also considered a look into the noise technologies that have been incorporated into real products. Figure 36 shows (in dots) certified noise level improvements of new Airbus aircraft since 2000. It shows that most of the new aircraft that entered service around 2015 are slightly noisier than what would have been required to follow the (grey) ACARE 2050 target line. The crosses in the Fig. 36 show intermediate projections made in Clean Sky2 by their Technology Evaluator process ${ }^{1}$ and indicate that current noise technology development is not sufficiently progressing to match the trend line towards the 2050 noise objective.

In order to resolve this gap, and in view of comparable research developments at the international level, establishing a more ambitious, more integrated framework is needed. It should support forward looking, longer term noise research to address a common goal, binging together the wide range of expertise needed across the board of solutions, from technology enablers to understanding impacts. The basic scope for such an effort has been provided through the SRIA Volume 2, which is addresses, beyond others, all the options of the ICAO CAEP Balanced Approach and is discussed in more detail in the next paragraph.

A major risk in achieving the 2050 noise goals is the current focus for $\mathrm{CO}_{2}$ reduction. The trade-off between especially $\mathrm{CO}_{2}$ and Noise (but also $\mathrm{NO}_{\mathrm{x}}$ ) can be significant, as is illustrated in Fig. $37^{2}$, which shows the inter-relational trend of the

\footnotetext{
${ }^{1}$ Airbus paper @ AEC 2020 conference Bordeaux.

${ }^{2}$ Prof Dimitri Mavris - Georgia Tech @ AEC 2020 conference Bordeaux.
} 
aircraft/engine environmental between Noise, $\mathrm{CO}_{2}$ and $\mathrm{NO}_{\mathrm{x}}$. It can be seen that if $\mathrm{CO}_{2} /$ Fuel Burn is prioritised, the Noise (as well as the $\mathrm{No}_{\mathrm{x}}$ ) performance will be compromised.

It can already be seen in current low $\mathrm{CO}_{2}$ research for air transport that some of the promising solutions of the future, are expected to have a trade-off between $\mathrm{CO}_{2}$ and noise. This is especially the case for:

- Advanced UHBR engine, where the short and thin nacelle needed for drag and weight reduction causes distorted flow into the fan, less liner area and -thickness, all increasing the noise.

- BLI Boundary Layer ingestion engines have an even more distorted flow into the fan, again increasing noise.

- Open Rotor architectures, inherently without nacelle to attenuate the noise, require new strategies and an unconventional approach towards annoyance reduction.

In conclusion, relative to the ACARE noise targets, the aircraft noise research effort can be considered as no longer on track to meet its objective, and thereby requiring significant support to get back on track. Actions critical to the ultimate success of the comprehensive overall approach, already summarised in the 2015 assessment, remain valid through the following recommendations:

- Bring the most promising Generation 2 noise reduction technology toTRL6, through an appropriate full scale validation effort across the board (engines, nacelles, landing gears, airframes).

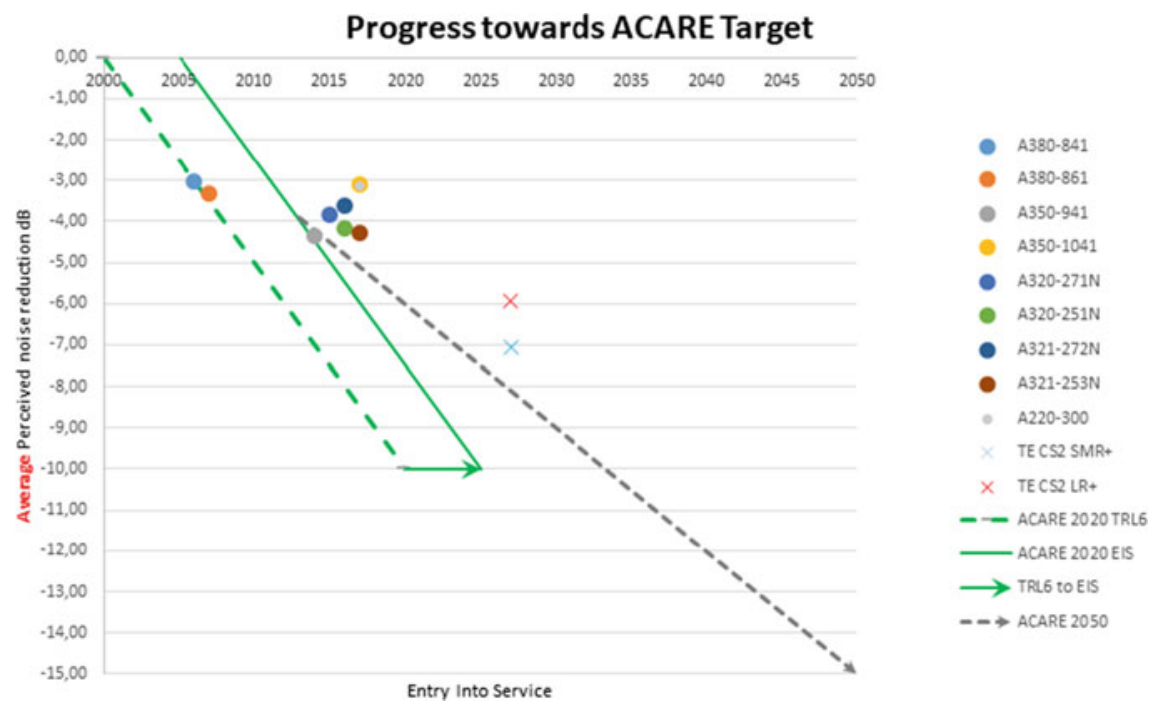

Fig. 36 Airbus recently certified aircraft and future projections relative to ACRE objectives 
Fig. 37 Example of aircraft/engine design space trade-offs on Noise $/ \mathrm{CO}_{2} / \mathrm{NO}_{\mathrm{x}}$



- Very significantly increase the effort dedicated to Low Noise Aircraft configurations noting that whilst programme prospects are better concerning novel engine architectures, the effort on aircraft configurations is significantly lagging behind.

- Take advantage of the sustained effort on low noise operational procedures to consolidate wider implementation capability.

Key uncertainties concerned the capability to support successful OPENAIR technologies to TRL6 through static and flight demonstrations and the needed emergence of ambitious multidisciplinary initiatives dedicated to environmentally friendly advanced aircraft configurations and design, which had gained momentum in other parts of the world.

It should also be pointed out that current progress results are valid for ducted turbofans engine concepts, while Open Rotor engine concepts had re-emerged in recent years as a serious option to provide the needed fuel burn benefits implied by the targets set for aviation $\mathrm{CO}_{2}$ emissions reduction. While the European research effort initiated in 2008 could already show significant achievements (see Fig. 21), it was outlined that the effort should be maintained through dedicated research aimed at rotor blade aeroacoustic design, engine/airframe installation and flow control techniques, in particular to consolidate such advances. 


\section{Addressing the Longer Term Objectives-Noise and the ACARE SRIA}

\section{Identifying the Conditions for a Successful Strategy Aimed at the 2050 Noise Target while Considering a Wider Noise Research Effort Allowing Full Implementation of the Balanced Approach}

Discussing implementation approach beyond the mere list of priority topics, the ACARE Strategic Research and Innovation Agenda (SRIA) has clearly stated that the $65 \%$ noise reduction targeted for 2050 "should be achieved through a significant and balanced research program. Such activity should be aimed at developing novel technologies and enhanced low noise operational procedures, complemented by a coordinated effort providing industry, airports and authorities with better knowledge and impact assessment tools. Such package will ensure that the benefits are effectively perceived by the communities exposed to noise from air transport activities.

Another objective of the SRIA is the capability to use the European airspace flexibly to facilitate reduced environmental impact from aircraft operations in the context of an air traffic management system allowing 24-h efficient operation of airports. Investigating and understanding the conditions allowing night-time operations from a community noise standpoint is certainly a pre-requisite in that regard.

Two workshops organised by X-NOISE under the ACARE auspices supported further development of a way forward (Future Trends in Noise Research, Brussels, October 2014 and Managing Aviation Noise Impacts-Mapping Future Research Priorities, Iasi, May 2015).

In the process, a conceptual roadmap to achieve the ACARE 2050 noise objectives within a 24/7 operations context has been defined (see Fig. 38), it does associate technological and operational solutions coupled with a significant effort aimed at noise effects on the communities:

- Capable of achieving the $65 \%$ noise reduction target set for 2050 when associated with novel aircraft / engine architectures

- Contributing to the «24/7 operations» goal through significant reduction of community impacts.

To address the key issues put forward by the workshops participants, the added value of a coordinated and integrated approach at European level was strongly emphasized. Effective engagement of stakeholders in research, joining efforts, sharing data and strategic advice was strongly advocated during the workshops. The basic features of a coordinating structure embedded in the effort discussed above has then been developed. It should among other activities:

- Coordinate research activities related to aviation noise through common national/ EU projects roadmap, progress assessments versus the ACARE targets, stimulate appropriate international cooperation and dissemination. 


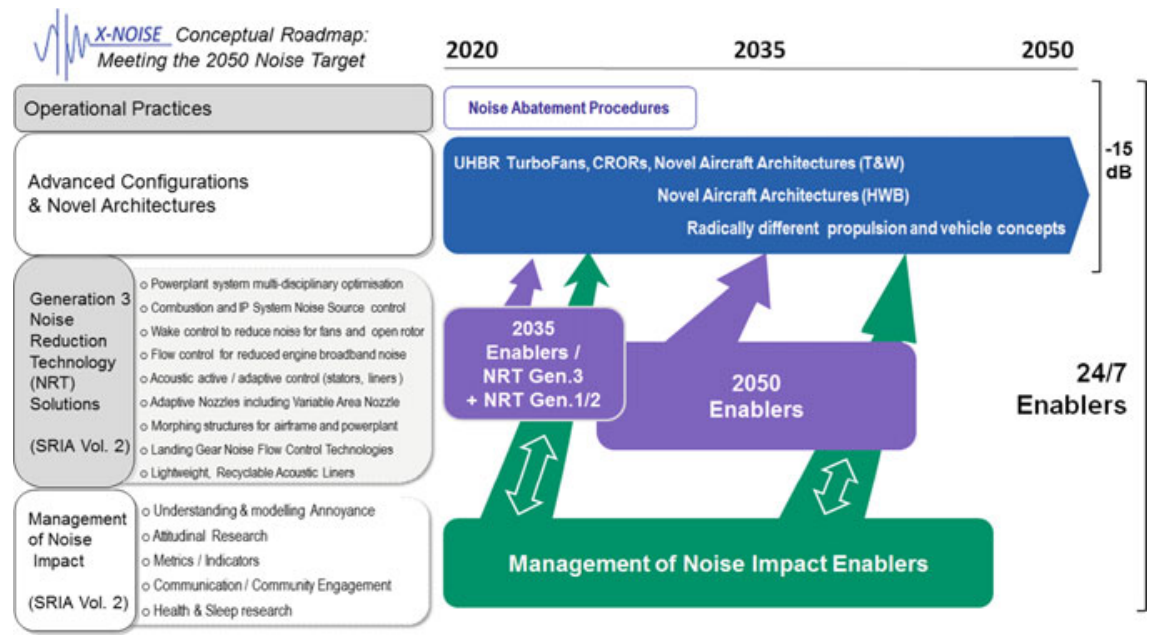

Fig. 38 Conceptual Roadmap to 2050 noise targets vs ACARE SRIA Vol.2 noise solutions

- Through shared strategic vision with on-going and planned national and self funded efforts, ensures gaps and priorities are being addressed altogether to achieve the programme technical and scientific objectives

- Establish a Noise Effects Knowledge Base Covering Long Term / Short Term Annoyance and Sleep Disturbance, Capable to bring in data from other compatible studies (national and international)

- Ensure that the most recent knowledge on noise impacts and annoyance in particular, is reflected in the criteria used for steering the technology effort, with the aim of capitalising on reduced noise at source to provide further effective improvement for the communities

- Rely on an advisory board involving stakeholders and authorities, thus closely associated with the proposed research initiative.

At this occasion, an overview of community noise effects research carried out in European countries was presented. It was noted that half of the overall national funding was dedicated to Health alone and that other aspects such as annoyance and sleep would strongly benefit for increased support at European level. It was also recommended that wider international cooperation be sought, in such areas where knowledge development is not concerned with competitive and industrial property issues.

In fact, several European experts and scientists participated in the ICAO Environmental Impacts workshop held February 2015 in Washington DC which ultimately led to a white paper on noise impacts presented at the CAEP/10 meeting (February 2016). Conclusions related to sleep disturbance and annoyance read as 
follows: "Undisturbed sleep is a prerequisite for high daytime performance, wellbeing and health. Aircraft noise can disturb sleep and impair sleep recuperation. Further research is needed to (a) derive reliable exposure-response relationships between aircraft noise exposure and sleep disturbance, (b) explore the link between noise-induced sleep disturbance and long-term health consequences, (c) investigate vulnerable populations, and (d) demonstrate the effectiveness of noise mitigation strategies."

"There is substantial evidence that aircraft noise exposure is associated with annoyance indicators, and exposure-response relationships have been derived to estimate the expected percentage of highly annoyed persons at a community level. Still, several personal and situational factors importantly affect the annoyance of individuals. Recent evidence for an increase in the annoyance response at a given exposure level indicates the need for updating exposure-response curves based on recent studies using harmonized methods, as well as verifying the circumstances leading to a heightened community response." It should also be noted that the World Health Organisation WHO has issued new recommendations in 2018 for environmental noise in the European region, including quite low exposure thresholds for avoiding health impacts resulting from Aircraft Noise. This confirms the findings made earlier on the higher annoyance perceptions from air traffic than from other transport modes like road or rail.

Land-Use Planning (LUP) was also discussed. The CAEP/5 meeting (2001) endorsed a balanced approach to aircraft noise mitigation (known as ICAO Balanced Approach), one pillar being improved land use planning and control. Years later, LUP is the only pillar of the Balanced Approach that is perceived as not delivering according to expectations.

One reason for such a situation lies in the lack of an explicit indicator to measure progress and then LUP contribution to the evolution of the noise situation around airports. Not delivering according to expectations also creates significant barriers to airport expansion, generating situation of conflict between several aviation stakeholders, including opportunities for complaints. Few and isolated research projects have tackled LUP related issues during the last decade, while the pressure and airports constraints to expansion has grown exponentially.

Another reason to improve LUP is to assist the ACARE noise goal on "no impacted people outside airport boundaries", or "no impacted people inside the 65 Lden contour, an objective also recently adopted by the USA CLEEN III project. Proper LUP is one of the means to achieve this goal, but delegated and scattered LUP responsibilities in many countries make it difficult to consolidate benefits from these measures. On the contrary, there is a severe risk at this moment that the number of impacted people increase due to conflicting policies in the field.

Research shall definitely help establish a process for assessing the effectiveness of land use planning as a function of time and evolution of other aspects of the Balanced Approach. A current challenge is to develop guidance material for policy makers and communities to encourage optimally compatible land-use around airports, as a critical part of any successful noise control strategy. Ensuring at existing airports that further residential developments do not endanger reduction of noise 
exposure already achieved (prevention method) constitute a key topic for investigation, while conversion of incompatible land-use shall remain a permanent concern. Useful research aimed at policy makers and non-specialists should then include a compact, practical, easy to understand and easy to use toolbox and a consistent set of indicators to evaluate the success of integrated land use in a sustainable airport context.

In summary, such research shall propose innovative and flexible land use management schemes for future airport developments. Associated tools will address support to decision making, information and community awareness. Interdependencies between noise and emissions may be also considered, as LUP is equally important for noise management as it is for controlling airport local air quality.

The concept behind the ANIMA project is clearly borne out of these conclusions, addressing the wider research agenda associated airports and communities issues while providing an opportunity for coordination with other efforts aimed at source noise reduction and moving the definition of a detailed global research strategy forward.

Remaining on the strategic aspects, as the focus of this chapter, the ANIMA work programme clearly answered the expressed request to establish a common strategic research roadmap for aviation noise reduction, addressing the development of new technologies and methodologies.

As such, the ANIMA project has put in place a collaborative process to establish and update a common strategic research roadmap through a scenario-based approach associated with a dedicated simulation process. Keeping in perspective the 2035 timeframe for the sake of the exercise, efforts have aimed at developing a roadmap covering all concerned areas of research and assess its elements based on an enhanced set of criteria including impacts driven targets. The role of this activity is shown on Fig. 39 and detailed in the next section.

\section{Establishing the Common Strategic Research Roadmap for Aviation Noise Reduction}

Under the support of the ANIMA project, the European aviation noise research community known as XNOISE has expanded the roadmaps towards the reduction of aviation noise annoyance. Besides the traditional "source noise reduction" roadmaps, a way forward has been defined on a range of associated elements like noise impact understanding, airport management and enablers to support the proposed solution contributors. Starting from a set of available roadmaps, a harmonisation has been conducted on the format and layout of the roadmaps. Taken into account the technology status of 2020 brought by recent projects and activities, a vision for the way forward on each element of the roadmap has been developed and consulted with the network. The final version will be published at the end of the ANIMA project (Fig. 40).

In order to verify if the roadmaps are sufficiently challenging, a scenario based approach is applied. Figure 41 provides an overview of the technology contributions 

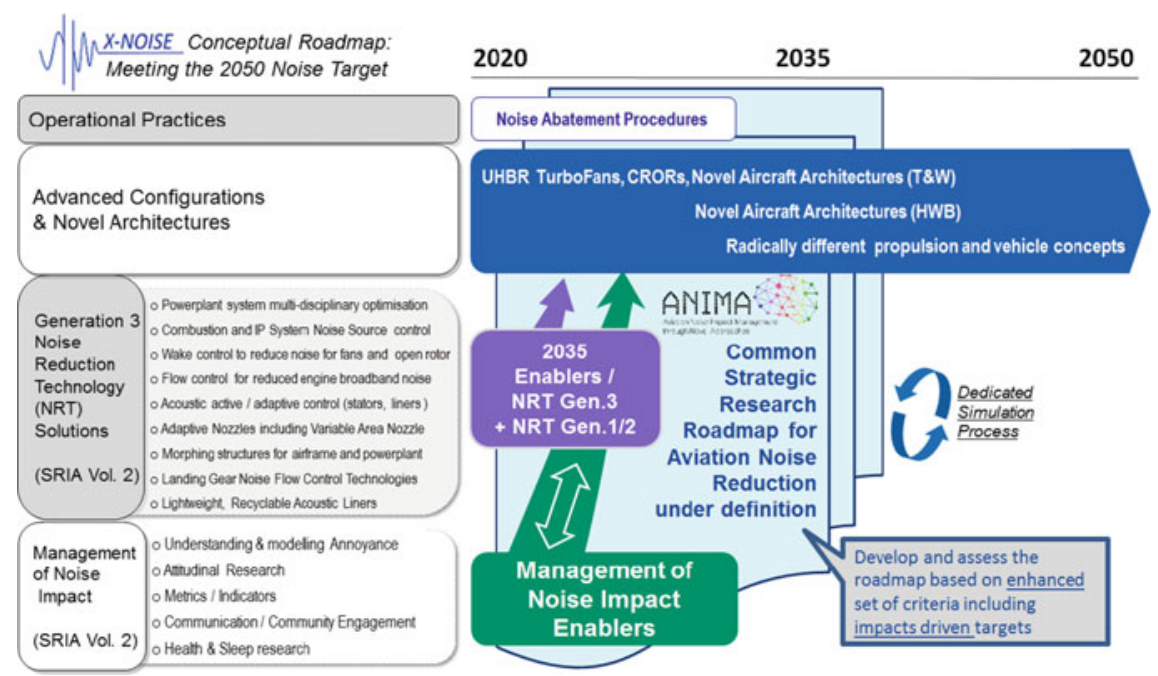

Fig. 39 Role of ANIMA in developing the noise research strategy for 2035


Fig. 40 Roadmap definition and harmonisation

that are considered for implementation into the scenarios. Besides these source noise technologies, the scenarios will also include Noise abatement procedures and Land use planning. The results will be evaluated for a set of 8-10 airports, representing small, mid-size and large European airports.

Figure 42 shows the list of roadmaps developed and the major topics within each roadmap. For each topic, a list of sub-topics describes the current TRL status and a consolidated expert view on how each activity could be further matured to support 




Fig. 41 ANIMA Technology matrix

the mission of achieving an air transport system that can sustainably achieve 24/7 operation.

\section{Community Building}

\section{General Overview}

As a main pillar of their global coordination activities, X-NOISE, then ANIMA have steadily brought together over the last 20 years a technical and scientific community with capability to advance aviation noise research beyond the state of the art. This has been achieved through 3 key objectives:

- Identifying and mobilising the best expertise all over the European Union and Associated States, addressing multi-disciplinary needs to support individual projects.

- Growing the base of SMEs involved in upstream research

- Supporting the global environmental research agenda of the EU and assessing progress made towards the ACARE targets, through wide-ranging experts committees.

A network of national focal points (NFPs) has been established covering the EU and number of associated states. Working around a common set of well disseminated priorities and objectives, it has favored a better exploitation of innovative upstream 


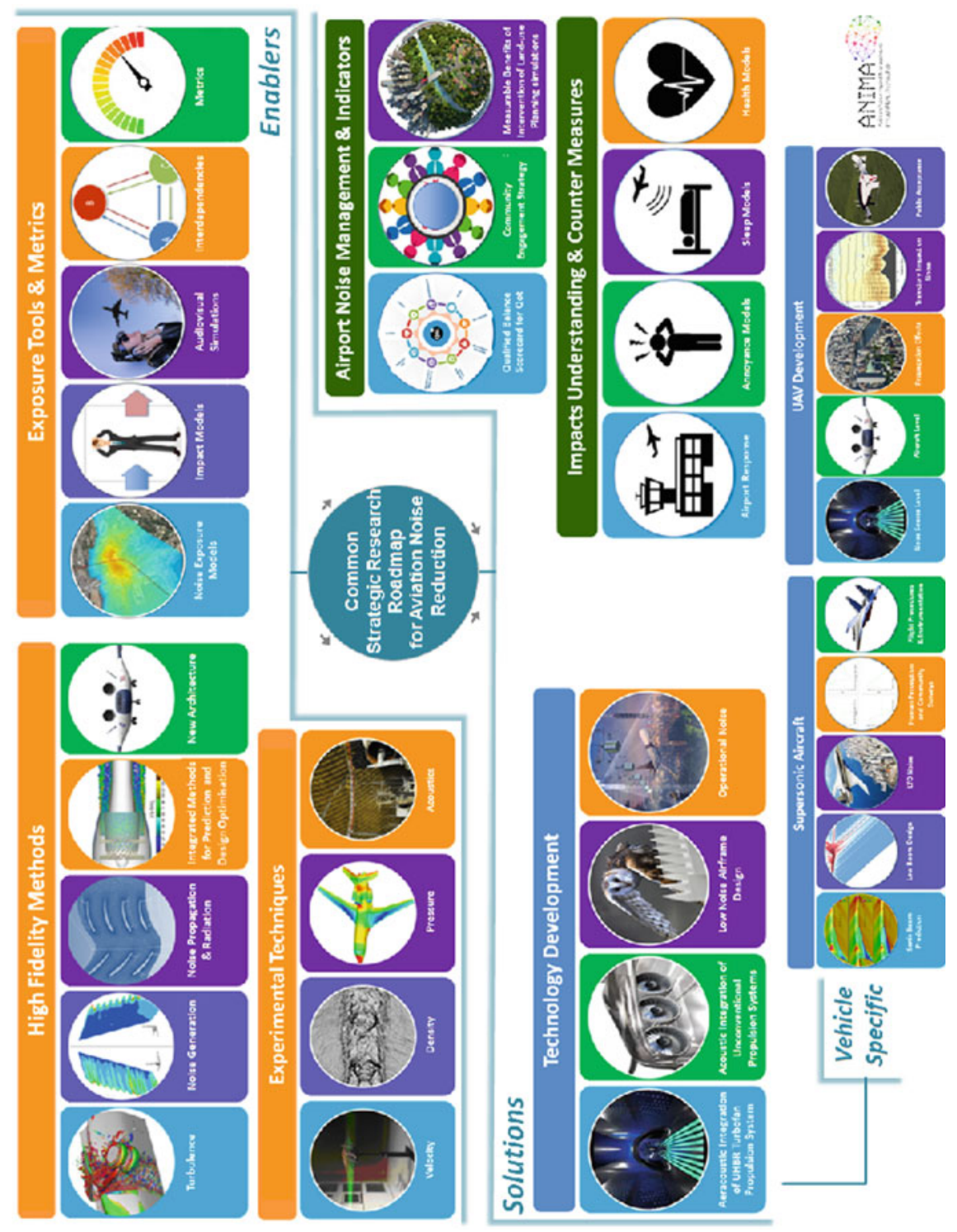

Fig. 42 ANIMA/XNoise roadmaps

research developed at national level into larger European projects aimed at downstream research. An overview of national efforts has also made been available based on successive reporting from all NFPs. This has also allowed a better dissemination at national level of EU projects research findings and acquired knowledge. 
With help from a bottom-up process seeking novel ideas through dedicated calls or brainstorming seminars as well as key dissemination actions such as an annual scientific workshop and web-based information features, this has made for an active scientific and technical community at European level, focused on improving aviation noise mitigation options.

Including all the parties that have been involved, up until the end of FP8 (Horizon 2020) in aviation noise research proposals submitted for EC funding, the grand total of participating organisations is now well over 200 since the early steps of the noise effort in FP4. As shown in Fig. 43, the SME trend in particular has kept growing, representing today more than $25 \%$ of that total figure.

A total of 26 European Union member states and associated states as well 4 "Third Countries" have been involved over the years in this effort, covering as shown on the projects roadmap (Fig. 7) source noise reduction, noise abatement procedures and management of noise impact.

Following the footsteps of successive X-NOISE CSAs, a dedicated "Global Coordination" activity is currently embedded in the ANIMA project. As such, former X-NOISE experts committees and National Focal Points network contribute to the ANIMA efforts aimed at establishing a "common strategic research roadmap for aviation noise reduction", as discussed in the previous section. Efforts have also been successful in extending the network of national focal point as discussed in the next section.



Fig. 43 Evolution of participation to noise project proposals 


\section{Integration of Research Community}

Initial efforts were developed in line with the EU policy addressing the development of the European Research Area (ERA). In the process, the concept of network National Focal Points (NFPs) emerged as a way to the reach a maximum of research teams potentially interested in aviation related noise research, while keeping the network deliberations to a reasonable size.

As an essential element of the 3-pillar approach described earlier, the network of National Focal Points (NFP) covers the European Union as well as neighboring countries involved in the EU research framework programmes. As such, it aims at achieving a better integration of the aircraft noise research community, looking forward to bringing in innovative ideas, fostering new collaborations and disseminating solutions. Ultimately, it support the development of an up-to-date picture of the aviation noise research effort including EU-funded and national projects, providing organisations interested in performing or exploiting aircraft noise research with better visibility. The expected output from this process is a research taking advantage of local expertise, also addressing local priorities as part of the whole effort.

As can be see seen on Fig. 44, network Focal Points contributing to this day to the network activity, ensure a wide coverage of EU states and neighbouring countries.



Fig. 44 European Aviation noise research network-Current Geographic coverage 
The role of NFP is expected to fit each country's specificity relative to the wider issues of mitigating aviation noise and providing solutions to reduce its impact. As an indication, it can typically involve the following activities:

- Summarise national aviation noise issues and associated research priorities

- Provide advice on the Common Research Roadmap for Aviation Noise Reduction developed by the network for the benefit of the EC.

- Identify relevant national programmes as well as potential input of interest for future European efforts and possible areas of collaboration within future projects.

- Contribute information to develop an overall roadmap of national programmes at European level

- Map and promote expertise of local researchers towards the European network as well as national authorities

- Inform local researchers on aircraft noise research strategic priorities at EU level.

The network membership is complemented by several experts committees gathering academia, research establishment and industry experts to contribute and review priorities for future research in the areas of technology as well as impact and balanced approach related issues. Figure 45 describes the process by which network participants support the definition and update of a common research roadmap.

Bringing participants together, a one day "Full Network " meeting has been organized every year since 2002 in co-location with a Scientific Workshop and annual Committee meetings. This has been an opportunity to involve and inform all network members. Typically, the meeting would proceed with the following programme of sessions:

- Update on the Common Research Roadmap for Aviation Noise Reduction

- Status on European Research Projects: reports from project coordinators

- Presentation of national research activities through a rotating scheme.

The Annual Scientific Workshop itself, jointly organized with the CEAS Aeroacoustic Specialist Committee, aims to address a priority topic relative to the research agenda. It is the occasion for the best experts in the field to present the most

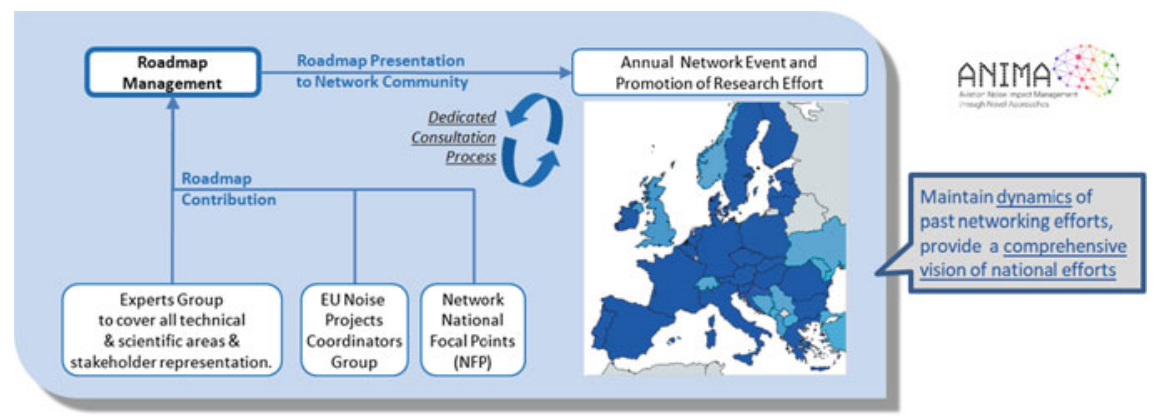

Fig. 45 Common research roadmap definition and update process 
recent findings as well as for the whole network community to gather and exchange information.

At last, to support a steady stream of participation from local researchers and feed into the strategic vision process, "Calls for Novel Ideas" have been featured, seeking innovative proposals and project ideas. The OPENAIR, ANIMA and ARTEM projects typically took advantage of such exercises in the early stage of proposal development.

Furthermore, to consolidate the vision developed through individual focal point reports, a study on national efforts was carried out across the countries involved in X-NOISE activities, related to noise reduction at source on the one hand and management of noise impacts on the other hand. This survey was conducted in view of preparing the October 2014 ACARE workshop "Future Trends in Aviation Noise Research" discussed earlier. An example of its findings is presented in Fig. 46.

A follow up exercise is on-going under the ANIMA project that will produce high level roadmaps of national activities consistent with the Common Strategic Roadmap developed in parallel.

At last, it should be mentioned that Egypt have been associated to X-NOISE activity up its end, with the objective of developing a regional Mediterranean network.

\begin{tabular}{|c|c|c|}
\hline & & mary \\
\hline & $\begin{array}{l}\text { Research EHlo } \\
\text { (exeluding to }\end{array}$ & $\begin{array}{l}\text { Tre } 2 \text { to } 5 \text { only } \\
\text { occale demos] }\end{array}$ \\
\hline ACARE 2035 Solutions & $\begin{array}{l}\text { 5-Year entimute } \\
\text { National the }\end{array}$ & $\begin{array}{l}\text { eccent } 8 \text { On-Goins } \\
\text { (2011- 2015) }\end{array}$ \\
\hline & $\begin{array}{l}\text { Completed } \\
\text { Research } \\
\text { Projects }\end{array}$ & Completed PhDs \\
\hline $\begin{array}{l}\text { Powerplant swstem multi-disciplinary optimisation (ind. efforts } \\
\text { in Computational AeraAcoustics and Source Modelling, except } \\
\text { combustion) }\end{array}$ & $35 \%$ & $46 \%$ \\
\hline $\begin{array}{l}\text { Development of noise prediction and integrated svstem } \\
\text { capability on UHER powerplants (incl efforts in Nocelle } \\
\text { Acoustcic Design and instollotion Effects Modelling) }\end{array}$ & $16 \%$ & $20 \%$ \\
\hline Combustion and IP System Noise Source Control & 8\% & 5\% \\
\hline Lightweight, Recyclable Passive Liners & 3N & $6 \%$ \\
\hline $\begin{array}{l}\text { Wake control to reduce interaction noise for fans (e.s. trailing } \\
\text { edge passive) and open rotor (e \&. pvilon blowing adaptive) }\end{array}$ & 5\% & 3\% \\
\hline Flow control for reduced turbomachinery broadband noise & $8 \%$ & 5\% \\
\hline Acoustic active control : Active stators, Active / Adagtive Liners & S\% & 5\% \\
\hline Adaptive Nourles including Variable Area Norzle & 3\% & $5 \%$ \\
\hline Morphing structures for airframes, nacelles and eneines & ox & OS6 \\
\hline Landing Gear Noise Flow Control Technologies & $\mathbf{8 *}$ & $5 \%$ \\
\hline 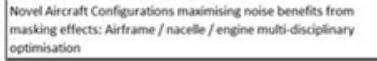 & 8* & $2 \%$ \\
\hline
\end{tabular}



Fig. 46 Vision of national activities aimed at Source Noise Reduction 


\section{Collaboration Efforts and Outreach}

As lasting organisations beyond the limited timeframe of individual projects, research networks ensure a much needed structural continuity aimed at longer term strategies. In linking together, the research networks also play a key role in addressing wider issues such as the global environmental research agenda of the EU. Outside the European aviation noise community, the network activity have aimed over the years at exchanges and external collaboration in four main directions:

- Interdependencies issues with its European counterparts focused on aviation gaseous emissions (AERONET and FORUM-AE CSAs)

- Synergies with the noise research priorities expressed by ground transportation European experts bodies (CALM CSAs)

- International collaboration involving joint projects with Russia and regular exchanges with transatlantic counterparts (USA, Canada, Brazil) as well as support to EU initiatives (CooperateUS, Cannape, SUNJET and ICARe CSAs).

- Information and expertise contribution to regulatory bodies (ECAC, ICAO CAEP).

\section{Noise-Emissions Interdependencies}

X-NOISE had established over the years a close working relationship with the aviation emissions community (AERONET, ECATS, FORUM-AE), resulting in several co-organised seminars $(2002,2008)$ and in a proposed roadmap for European Aviation Environmental Modelling, including the definition of a Durable Organisation Structure presented to ANCAT in 2013 (see Fig. 47).

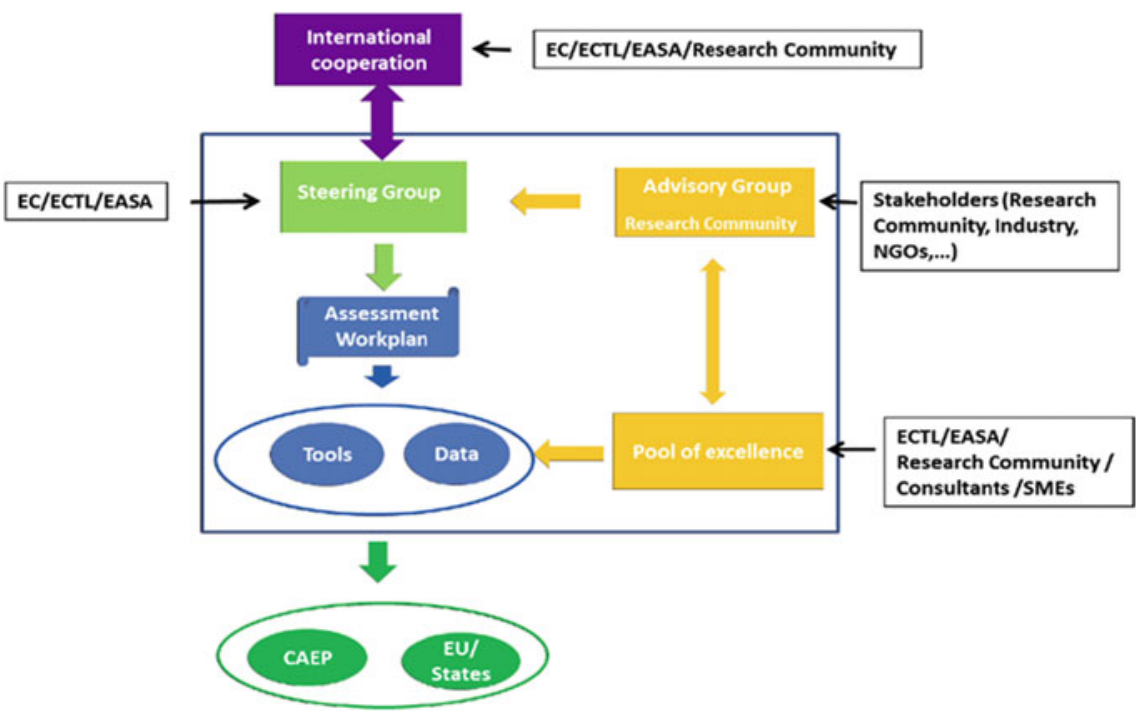

Fig. 47 Durable and cost efficient European Environmental Assessment Structure (EA2S) 


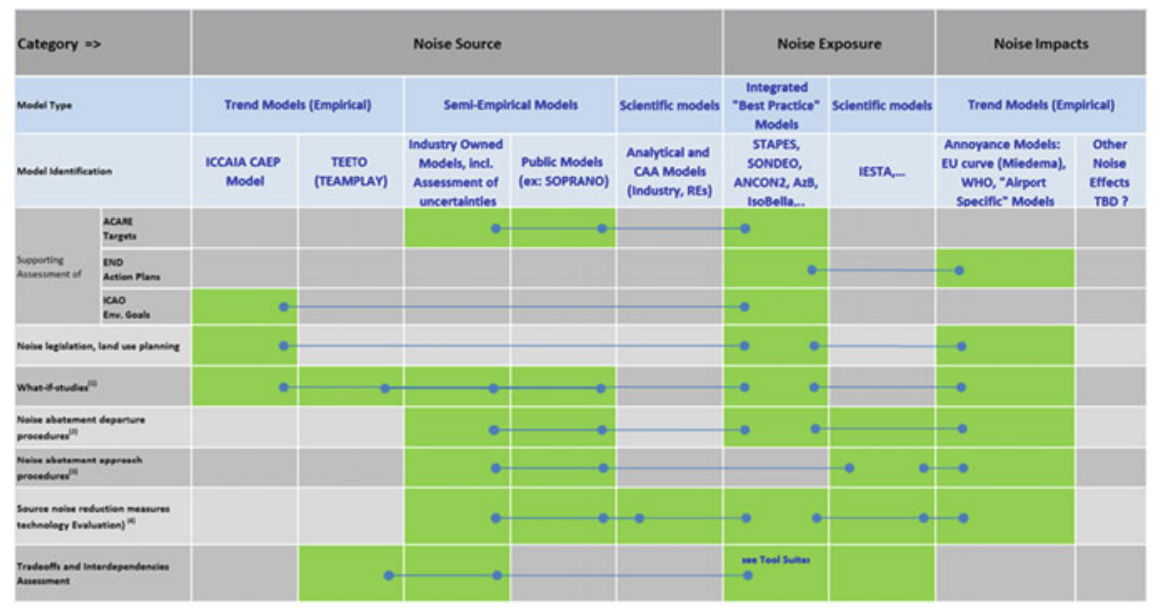

(1) Studies on changes in fleet mix, number of operations, airport structure etc.

(2) Capability to to perform flight performance calculations noise required

(3) Capability to model airframe noise required $(+(2))$

(4) Capability to model particular noise sources (jet, fan, airframe, gears) required

Fig. 48 Aviation Noise Models-Characteristics/Field of Application

As a follow-up action, a full picture of the situation on noise prediction models was developed for the 2016 Workshop on European Aviation Modelling Capabilities (Fig. 48).

\section{Synergies with European Research Policies on Ground Transportation}

In connection with the establishment of the Directive 2002/49/EC “ Assessment \& Management of Environmental Noise, the CALM initiative was the result of a close collaboration between the European Commission services responsible for developing the new European noise policy, DG Environment, and the DG Research. It aimed at ensuring that initiatives concerning research on noise reduction were in line with the requirements of the directive and vice versa.

The main CALM deliverable has been a strategy paper titled « Research for a Quieter Europe in 2020» first published in 2004 then updated in 2007. The CALM network expertise focusing primarily on ground transportation, it was advocated that a collaboration with X-NOISE was established in order for the noise research policy strategy to benefit from the work done for air transport within the ACARE framework. The strategy is expressed along two axes, perception and emission. While on the emission aspects (noise reduction at source), the proposed roadmaps are specific of transportation modes (i.e. X-NOISE/ACARE for air transport), the perception aspects priorities are identified across the board as shown on (Fig. 49).

Overall, an excellent level of collaboration was developed between ground and air transportation during these strategic exercises.

However, given the absence of a follow-up of CALM after 2007, it remains puzzling that no post-2020 overall European noise research strategy has been expressed so far in a similar way. 


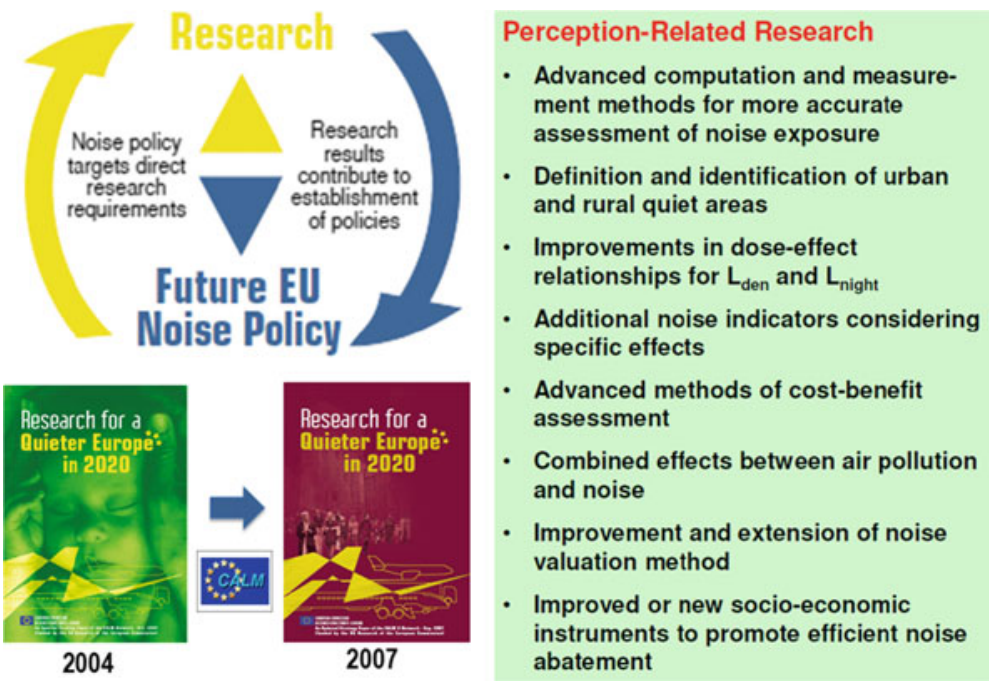

Fig. 49 Key aspects of European noise research strategy concerning perception

\section{International Collaboration}

Efforts aimed at international collaboration have focused in the first place on the countries featured in Fig. 1, with the understanding that counterparts pre-existed thanks to running research programmes in a similar area.

Over the years, with X-NOISE, then ANIMA support, a series of joint seminars organised through these counterparts have been held with US, Canada, Russia and Brazil. Links were also established with several CSAs involved in exploring international cooperation such CooperateUS, CANNAPE, SUNJET and recently ICARe.

As of FP6, this has led to participation in noise project proposals of US, Canadian, Japanese, Russian and Brazilian entities. Advantage was taken in particular of "Joint Calls" issued with Russia, Japan and Canada.

The ANIMA effort have recently focused on updating the topics of common interest and collaborated with ICARe to this end, completing in effect the three-point programme laid out for its "global coordination" activity (Fig. 50).

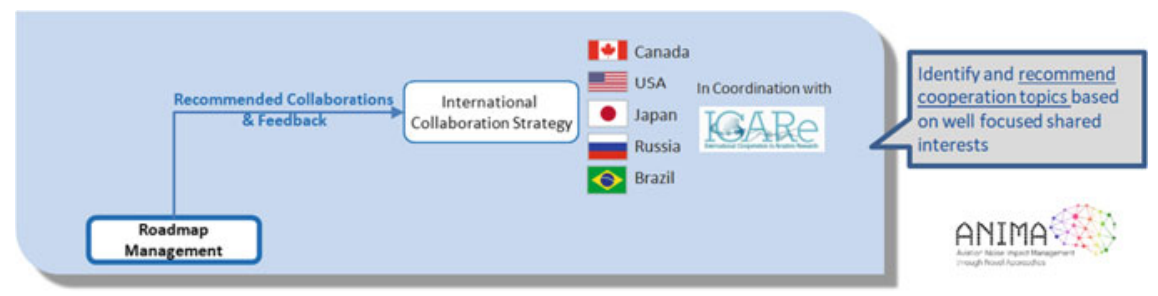

Fig. 50 International collaboration activity in ANIMA 
Along with the definition of quite varied interests depending on the countries involved (from technology to impacts), it was clear from all discussions held with counterparts in this context that bi-lateral focused research was favored over larger multi-lateral efforts.

The existence of well-identified counterparts is key in successfully investigating topics and conditions for international collaboration. In the case of noise, these fruitful discussions were facilitated by the occurrence of formal networks (US, Canada) or informal ones (integrated national research projects in Japan, Russia and Brazil). Networks collaboration have been in fact an important factor in identifying or aligning projects on shared priorities.

Organised since 2005, the 3AF / AIAA Aircraft Noise and Emissions Reduction Symposium (ANERS) has provided such opportunity for network exchanges at regular intervals (every two year). To figure out the interest in going a step further into maintaining some form of constant dialog, a "Network of Networks Seminar" was organised by X-NOISE, taking advantage of the ANERS event held in September 2015. Identified networks involved in aviation environmental research included:

- US FAA Center of Excellence ASCENT (formerly PARTNER): Noise Emissions, Alternative Fuels

- Canada Network of Excellence GARDN: Noise, Emissions

- EU X-NOISE CSA: Noise

- EU FORUM-AE CSA: Emissions

- EU CORE-JetFuel CSA: Alternative Fuels

- ECATS International Association: Emissions

- ANNA (Aircraft Noise Non Acoustic effects): Noise.

The seminar session gathered representatives from the networks mentioned above as well as participants from Brazil, Russia, and Japan research programmes.

Following the debate, there was definite support for a yearly event dedicated to exchanges on international programmes, with a preference for the March to May slot. It was recommended that, while addressing the whole aviation environmental agenda, there should be a stronger focus on a specific topic, different at each event. The ANERS Symposium came close to the appropriate formula, but being organised by scientific societies (3AF, AIAA) with overheads and set conference organisation practices, the event programme somewhat lacked flexibility and remained conditioned by financial considerations.

In order to seek wider international involvement and participation, the capability to provide a Webinar option for abroad participants was put forward. At last, on years where a face to face event could not be organised, exchanging on international programmes by way of a webinar was recommended.

Unfortunately, the end of activity for the 3 European CSAs involved (X-NOISE, FORUM-AE, CORE-JetFuel) created a situation in which only ANIMA could further explore international collaboration, albeit in a very focused approach related to noise.

However, as could be verified through discussions during ANERS 2017 and ANERS 2020, the international interest is there for the network of networks formula provided appropriate support from the European side. 


\section{Information and support to regulatory bodies}

A discussed above, dedicated seminars supported the work of ECAC ANCAT aimed at Interdependencies modeling. In another area connected both to ANCAT and the Environmental Noise Directive (END), several seminars (2003, 2005, 2010, 2013) were organized to discuss and debate noise mapping techniques in an air transport context.

Since 2006, the network has coordinated the European input to the report on noise research update provided at each plenary ICAO CAEP meeting (every three year). This report covers altogether the research programmes shown in Fig. 1 and has also been featured in a summary form in the ICAO Environmental Report published those same years.

Moreover, three international technology seminars were organised to kick-off the preparation of important ICAO CAEP events such as the first ICAO Noise Technology Workshop and the first and second ICAO Independent Experts Noise Technology Reviews (2001, 2008, 2011). These involved specialists and regulators from US, Canada, Japan, Russia and Brazil in particular. Similarly, the network coordinated European noise projects input to the new Integrated Independent Experts Review (noise and emissions combined) performed in 2017.

\section{Lessons Learned}

Along the strategy implementation effort described in the previous section, a numbers of lessons could be acquired from successful initiatives as well as occasional setbacks. The regular oversight provided by the global picture on worldwide research and ways of dealing with such efforts in various countries also provided interesting perspectives.

\section{Reflecting on the Technology Focused Effort and the Extended Research Scope}

- Strategy wise, the EU competitive funding mechanism, while quite different from the top-down US approach to similar efforts, allowed the successful implementation of the phased approach established around the ACARE SRA and SRIA. The coordination layer provided by a noise dedicated CSA has allowed regular exchanges with ACARE in terms of future priorities as well as assessment of progress made. This layer will remain essential as the research effort widens its scope towards achieving the 2050 target.

- Large noise dedicated, industry-led projects (Ref SILENCER / AFLONEXT) have proven their capability to bring new technologies to TRL6 in a very effective and cost efficient approach. These large noise projects have also been successful in 
bringing on board a critical mass of multidisciplinary expertise in order to ensure a viable exploitation into an aircraft/engine, as production technologies needed to be matured in parallel to the noise technologies.

- However, a key observation has been that for these technologies to reduce noise further as a feature of the next engine/aircraft commercial programmes, a full scale demonstration such as engine static test or aircraft flight test was required to achieve this level of maturation. When dedicated funding for such demonstrations were not available, this created a situation where a number of promising technology solutions such as put forward by the OPENAIR project sat at TRL5 for some time, seriously restricting the panel of technologies able to support the satisfaction of the ACARE 2020 noise targets. As such, progress towards the ACARE Noise goals is not fully in line with expectations at this stage, which increases the risk that public acceptance will force authorities to take action against growth of air transport.

On a more global note:

- The whole effort involving some 35 projects in 25 years has associated industry, research establishments, academia and SMEs participants in a very collaborative manner, which led to a large number of medium size projects coordinated by research establishments.

- Thanks to networking / global coordination efforts:

- contributions to the ACARE SRA and SRIA were developed in similar collaborative fashion.

- the progressive extension of the research scope has been the opportunity for great collaboration between technology and impacts experts. The expected widening of the research calls for maintaining this approach in the future

- dedicated activities have been instrumental in establishing successful international cooperation channels.

- support to ICAO information activities on research and technology reviews have been timely and well perceived.

\section{Noise vs Emissions}

- Interdependencies between Noise and emissions $\left(\mathrm{CO}_{2} / \mathrm{NO}_{\mathrm{x}} /\right.$ Particles $)$ need to be quantified to provide visibility on how the trades could influence the achievement of environmental objectives. Such quantification is recommended from both an aircraft/engine design point of view as well as for the operational aspects of air transport.

- On the technical aspects of trades and interdependencies, an active dialog has been maintained with the emissions/modelling community. However, the coordination structures (CSA) handling these aspects have been absent the last few years. This is 
a problem to consider when time comes for the next environmental goals progress assessment.

- Moreover, the European priority for aviation noise annoyance reduction appears strongly reduced given the changing focus on climate change (Green Deal). Experience tells that when funding is provided for a wider "environmental" scope, stakeholders tend to apply a limited part of it towards noise reduction.

\section{EU Transport Noise Policy}

- An excellent level of collaboration was developed between ground and air transportation at the occasion of the successive strategic exercises handled by the CALM network in preparation of the strategy paper « Research for a Quieter Europe in 2020». However, given the absence of a follow-up of CALM after 2007, it remains puzzling that no post-2020 overall European noise research strategy has been expressed so far in a similar way.

- In the absence of such a long term shared vision, dilution of funding through clustering of efforts with all transport modes remains a clear concern.

Open Access This chapter is licensed under the terms of the Creative Commons Attribution 4.0 International License (http://creativecommons.org/licenses/by/4.0/), which permits use, sharing, adaptation, distribution and reproduction in any medium or format, as long as you give appropriate credit to the original author(s) and the source, provide a link to the Creative Commons license and indicate if changes were made.

The images or other third party material in this chapter are included in the chapter's Creative Commons license, unless indicated otherwise in a credit line to the material. If material is not included in the chapter's Creative Commons license and your intended use is not permitted by statutory regulation or exceeds the permitted use, you will need to obtain permission directly from the copyright holder. 